\title{
Artículos
}

\section{Las cifras de la documentación en España: 2002}

\author{
Por Emilio Delgado López-Cózar
}

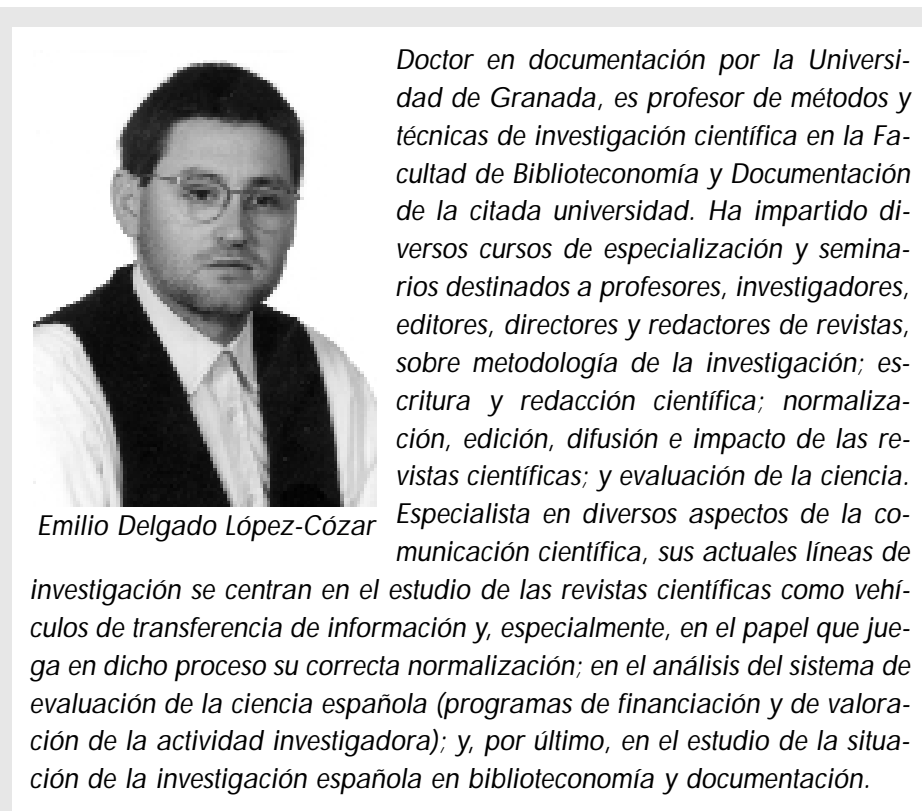

Resumen: Se ofrece una radiografía del estado de las profesiones y disciplinas documentales en España en 2002. Se aportan datos estadísticos sobre el número y tipo de bibliotecas y archivos españoles, y sobre los profesionales en ejercicio atendiendo a su distribución geográfica, formación y dedicación. Se identifican y caracterizan los órganos responsables de la administración bibliotecaria y documental española, las asociaciones profesionales y sociedades científicas en que se agrupan los profesionales, los congresos y jornadas científicas en que se reúnen. Se pasa revista a la formación universitaria especializada describiendo los centros existentes, los niveles de estudios y aportando datos estadísticos sobre el número de estudiantes que los cursan y el de profesores que los imparten. Se proporcionan los rasgos de los medios de comunicación profesional y concretamente se describen las editoriales, los boletines informativos, las revistas científicas y foros electrónicos. Se cuantifica la producción editorial especializada: libros, artículos en revistas y comunicaciones a congresos tanto a escala nacional como internacional. Se concluye informando sobre la cantidad de investigación producida en el campo a través de la lectura de tesis doctorales, de artículos de investigación publicados y los proyectos de investigación financiados.

Palabras clave: Archivos, Bibliotecas, Estadísticas, Administración, Profesión, Bibliotecarios, Asociaciones profesionales, Sociedades científicas, Congresos, Educación, Diplomatura, Licenciatura, Doctorado, Estudiantes matriculados, Estudiantes graduados, Profesores, Editoriales, Revistas científicas, Boletines informativos, Foros electrónicos, Producción editorial, Producción científica, Investigación, Tesis doctorales, Biblioteconomía, Documentación, Archivística, España.

\section{Title: Library and information figures in Spain: 2002}

\begin{abstract}
The state of the Spanish LIS profession and specialities in 2002 is reviewed. Statistical data is provided about both the number and type of Spanish libraries and archives as well as of practising professionals, according to geographic distribution, training and job description. Spanish library and information authorities are identified as well as professional associations and learned societies and conferences held. University education is also examined with descriptions of existing institutions, degree levels and data on student enrolment and teachers. The primary media for professional communication are described, in particular, publishers, bulletins, scientific journals and electronic fora. Publishing output is quantified: books, journal articles, and conference papers both at national and international levels. Finally, research in the field is analysed through the total of Ph. D. dissertations presented, research articles published and research projects funded.
\end{abstract}

Keywords: Archives, Libraries, Statistics, Public administration, Professionals, Librarians, Associations, Learned societies, Conferences, Education, Undergraduate, Master's degree, Doctorate, Students, Graduates, Teachers, Scientific literature, Publishers, Periodicals, Scientific journals, Newsletters, Discussion lists, Book production, Scientific publication output, Research, Dissertations, Archival science, Library and information science, Spain.

Delgado López-Cózar, Emilio. “Las cifras de la documentación en España: 2002”. En: El profesional de la información, 2003, septiembre-octubre, v. 12, n. 5, pp. 344-367.

Artículo recibido el: 21-02-03

Aceptación definitiva: 23-04-03 


\section{Introduc ción}

Tomando prestado el título de una reciente obra que refleja la situación de la cultura española, y siguiendo su planteamiento, pretende este trabajo, de igual manera, radiografiar el estado actual del sector documental en España, entendido éste en sentido amplio, abarcando todas las profesiones y disciplinas documentales.

Un trabajo de este tipo debe partir necesariamente del inventario de los archivos, bibliotecas y demás servicios informativos que conforman la infraestructura documental. En segundo lugar, ha de reflejar el entramado institucional que rige los destinos y que marca las directrices de la política documental del país. En tercer lugar, debe fijar el tamaño, extensión y complejidad de la comunidad profesional y el grado de organización social alcanzado por la misma a través de las asociaciones profesionales y sociedades científicas. En cuarto lugar, pretende caracterizar la educación que habilita para el ejercicio de la profesión, describiendo los centros existentes y los niveles de estudios e indicando el número de estudiantes que los cursan y el de profesores que los imparten. En quinto lugar, debe ocuparse de mencionar los canales de comunicación científica y profesional (congresos, editoriales especializadas, boletines informativos, revistas científicas, foros electrónicos) que actúan como cauces de expresión y de información de la comunidad documental. Por último, analizará la literatura profesional y científica ofreciendo datos sobre la capacidad de generar conocimiento científico y profesional.

\section{«Un dato elocuente de la juven- tud del sector documental es- pañol lo constituye el hecho de que la mayoría de las bibliote- cas en España se ha creado en los últimos 30 años»}

Antes de describir las fuentes utilizadas quisiera resaltar las limitaciones del análisis. Por sus propias características, las fuentes empleadas retratan muy bien el sector público pero no el privado, especialmente en todo lo referente a empresas y consultoras dedicadas a la documentación en cualesquiera de sus manifestaciones, ejercicio libre de la profesión, así como unidades informativas financiadas con fondos privados.

\section{Fuentes y métodos}

Los datos sobre los que se edifica este trabajo se han recogido de recursos variopintos, en unos casos primarios y en otros secundarios.
- Los datos estadísticos sobre los archivos y bibliotecas y su personal se han extraído de la Estadística de bibliotecas de 2000, producida por el INE, y de la Estadística de archivos de 1998 producida por el el Centro de Información Documental de Archivos, ambas accesibles desde la web del INE. Conviene advertir para efectuar una correcta interpretación de los datos que las fuentes de información disponibles son parciales y con diferente grado de actualización. El ámbito de la estadística bibliotecaria lo constituyen todas las bibliotecas del territorio español, cualquiera que sea su dependencia administrativa, excepto las privadas (cuya utilización no está permitida al público) y las escolares. La estadística de archivos cubre razonablemente bien los organismos dependientes de las administraciones públicas y los eclesiásticos pero en menor medida los del sector privado, suministrando nula información sobre sus principales características, servicios y personal. Por tanto, las unidades informativas, ya sean bibliotecas, archivos o centros de documentación, de carácter privado no se reflejan adecuadamente en los datos presentados, si bien históricamente ha sido un sector de poco peso cuantitativo en la infraestructura documental española.

http://www.ine.es

—La información relativa a la administración bibliotecaria y a las asociaciones profesionales se ha compendiado a partir de las páginas web mantenidas por las propias instituciones.

- Los datos estadísticos sobre educación se han extraído de la Estadística de la enseñanza superior de 2000 y de los Avances la estadística de la enseñanza universitaria de 2001-2002. La información sobre los centros educativos y departamentos universitarios se ha recogido de las páginas web de dichas instituciones así como de las mantenidas por el Consejo de Coordinación Universitaria.

http://www.mec.es/consejou/index.html

- La información sobre editoriales, revistas, boletines informativos y foros electrónicos se ha extractado de diversas fuentes electrónicas y ha sido contrastada con las páginas web mantenidas por las propias instituciones patrocinadoras.

-Para identificar la literatura científica circulante se ha realizado una búsqueda en la base de datos del Isbn empleando los descriptores "biblioteconomía" y "documentación". Se ha recurrido a este recurso por ser la base de datos que proporciona información más exhaustiva y actualizada de la producción libraria, aunque son bien conocidas sus limitaciones para realizar búsquedas temáticas. Por consiguiente, es muy posible que no se haya capturado toda la información pertinente. La producción científica internacional se 


\begin{tabular}{|c|c|c|c|c|c|c|c|}
\hline | otal & $\begin{array}{c}\text { Total } \\
\text { blbilotecss } \\
1.103 \\
\end{array}$ & $\begin{array}{c}\text { Administración } \\
\text { Ceneral del tstado } \\
\text { 82y }\end{array}$ & $\begin{array}{c}\text { Administraciòn } \\
\text { autonờnica } \\
2.449\end{array}$ & $\begin{array}{c}\text { Diputaciones } \\
\text { provinciales, } \\
\text { cablidios... } \\
921 \\
\end{array}$ & $\begin{array}{c}\text { Ayuntamientos y } \\
\text { entidades locales } \\
3.848 \\
\end{array}$ & $\begin{array}{c}\text { Privada (usuarios, } \\
\text { empresas...) } \\
1.244 \\
\end{array}$ & $\begin{array}{l}\text { No consta } \\
\text { thanciación } \\
213 \\
\end{array}$ \\
\hline Narinnalcs & 1 & 1 & 0 & 0 & 0 & 0 & 0 \\
\hline $\begin{array}{l}\text { Otras importantes } \\
\text { no cespecislizadas: }\end{array}$ & $680^{\circ}$ & 35 & 57 & 3 & 2 & 3 & 2 \\
\hline Publicas & 4.722 & 356 & 1.502 & 774 & 3.687 & 355 & 147 \\
\hline tiencrales & $4.08 /$ & 18 & 1.398 & 758 & 3.634 & 213 & 126 \\
\hline $\begin{array}{l}\text { Des organizmos } \\
\text { militares }\end{array}$ & 26.3 & $25 B$ & 0 & 0 & 0 & 0 & 5 \\
\hline $\begin{array}{l}\text { De huspilales } \\
\text { (no especialicautas) }\end{array}$ & 66 & 19 & 30 & 2 & 1 & 14 & 3 \\
\hline $\begin{array}{l}\text { De institudiones } \\
\text { penitenciarias }\end{array}$ & 68 & Ss & 9 & 0 & 0 & 2 & 4 \\
\hline De colegio mayor & 90 & 1 & 16 & 2 & 2 & 61 & 6 \\
\hline Otras víblicass & 148 & 2 & 49 & 12 & 50 & 62 & 3 \\
\hline $\begin{array}{l}\text { Instituciones de } \\
\text { ensefianza superior }\end{array}$ & 610 & 60 & 421 & 46 & 46 & 135 & $1 /$ \\
\hline Lniversitarias & 51.3 & 51 & 39.3 & 15 & 11 & 116 & 13 \\
\hline No univergitarias & 67 & 6 & $.3 B$ & 1 & 2 & 19 & 1 \\
\hline Especializadas & 1.702 & 373 & 469 & 98 & 113 & 751 & 49 \\
\hline Roligicases & 166 & 2 & 6 & 4 & 6 & $14 /$ & 11 \\
\hline $\begin{array}{l}\text { 1)e organtemns do } \\
\text { la Administracioin }\end{array}$ & 200 & 1.37 & 60 & 9 & 3 & 1 & 1 \\
\hline $\begin{array}{l}\text { De centros de } \\
\text { investigsecioun }\end{array}$ & 194 & 103 & 42 & 21 & 7 & 55 & 3 \\
\hline $\begin{array}{l}\text { Asoclacliones y } \\
\text { coleglos protesionales }\end{array}$ & 296 & 1 & 8 & 8 & 11 & 280 & 9 \\
\hline De ompremas & 89 & 5 & 4 & 0 & 4 & B1 & 0 \\
\hline De arctivus y museus & 233 & 32 & 115 & 32 & 45 & 35 & 4 \\
\hline Otras especislizadas & 516 & 93 & 234 & 24 & 37 & 149 & 21 \\
\hline
\end{tabular}

Tabla 1. Bibliotecas españolas según su financiación por tipo de biblioteca en el año 2000. Fuente: Instituto Nacional de Estadística. Estadística de bibliotecas 2000.

* La suma de este apartado es errónea.

ha extraído de las bases de datos del ISI (Science Citation Index, Social Science Citation Index y Arts \& Humanities Citation Index). La estrategia de búsqueda fue la siguiente: en el campo Address se consigó la ecuación: "spain and (librar* or document* or archiv* or bibliot*)". Se limitó la búsqueda a los años 2001 y 2002. Las consultas se efectuaron el 07-02-03.

-En cuanto a las tesis doctorales, las carencias de Teseo (lentitud en la alimentación de registros, lagunas en la cobertura, falta de coherencia en la indización), la base de datos que registra desde 1976 las tesis doc- torales defendidas en España, obligó a emplear estrategias de búsqueda complementarias: consulta de los catálogos de las bibliotecas de las escuelas y facultades donde se imparten estudios de ByD (biblioteconomía y documentación) y una encuesta a los directores de los departamentos universitarios de ByD.

\section{La infraestructura documental}

Según la estadística de bibliotecas elaborada por el INE (tabla 1) en España existían, en el año 2000, 7.103 bibliotecas que tenían abiertos 8.208 puntos de servi-

\begin{tabular}{|c|c|c|c|c|c|c|c|}
\hline & Total & $\begin{array}{l}\text { Adninistración } \\
\text { central }\end{array}$ & $\begin{array}{l}\text { Legislativos } \\
v \text { consultivos }\end{array}$ & $\begin{array}{l}\text { Administración } \\
\text { autonómica }\end{array}$ & $\begin{array}{l}\text { Administración } \\
\text { local }\end{array}$ & $\begin{array}{l}\text { Administración } \\
\text { de iusticia }\end{array}$ & $\begin{array}{l}\text { Camaras } \\
\text { adrarias }\end{array}$ \\
\hline Total & 35.517 & - & - & - & - & - & - \\
\hline $\begin{array}{l}\text { Administración } \\
\text { Ceneral del Estado }\end{array}$ & 13.537 & 1.780 & 6 & 374 & 6.730 & 4.783 & 1.414 \\
\hline telesiásticos & 14.126 & - & - & - & - & - & - \\
\hline $\begin{array}{l}\text { Económicos: empresas } \\
\text { v entidades bancarias }\end{array}$ & 2.496 & - & - & - & - & - & - \\
\hline Centros docentes & 1.843 & - & - & - & - & - & - \\
\hline $\begin{array}{l}\text { Asociaciones y } \\
\text { colegios profesionales }\end{array}$ & 448 & - & - & - & - & - & - \\
\hline Otros ${ }^{\lambda}$ & $3.06 /$ & - & - & - & - & - & - \\
\hline
\end{tabular}

Tabla 2. Archivos españoles según tipo y dependencia orgánica en 1998.

Fuente: Centro de Información Documental de Archivos. Anuario estadístico de España.

* Incluye archivos de centrales sindicales y organizaciones patronales; asociaciones recreativas deportivas y culturales; partidos políticos; medios de comunicación; centros asistenciales y benéficos y ONGs; centros hospitalarios; instituciones científicas y de investigación; particulares/ nobiliarios; fotográficos y comunidades de regantes y sindicatos de riego. 
cio, de los cuales 8.042 eran fijos y 166 móviles. Por tipo, las dominantes son, como no podía ser de otra manera, las públicas (66\%), seguidas de las especializadas (24\%) y de las de instituciones de enseñanza superior (9\%). Como claramente se aprecia en la tabla 1 es la administración pública la que lleva el peso financiero de las mismas y, muy especialmente, los ayuntamientos y entidades locales que financian el $54 \%$, la administración autonómica (34\%), las diputaciones provinciales y cabildos insulares (13\%) y la Administración General del Estado (12\%). La financiación privada, ya sea a través de empresas o cobro de cuotas a sus usuarios, se extiende al $18 \%$ de las bibliotecas.

Un dato extraordinariamente elocuente de la juventud del sector documental español lo constituye el hecho de que la mayoría de las bibliotecas en España se ha creado en los últimos 30 años. El 70\% ha iniciado su funcionamiento a partir de 1970 , siendo la década de los ochenta el momento de más febril actividad (el $32 \%$ de los centros fue creado en dicho período).

La biblioteca española dominante es de tamaño pequeño o mediano (el 75\% alcanza una superficie de menos de 250 metros cuadrados y el $61 \%$ tiene menos de 200 metros lineales de estantes), y de acceso libre (74\%), si bien existen diferencias apreciables entre los distintos tipos.

Las comunidades autónomas con mayor número de bibliotecas son: Andalucía (955), Cataluña (873), Madrid (790), Comunidad Valenciana (657), Galicia (655), Castilla y León (512), Extremadura (469), Castilla La Mancha (453), País Vasco (427), Aragón (350), Canarias (247), Baleares (178), Asturias (148), Murcia (139), Navarra (128), Cantabria (57), La Rioja (36), Ceuta y Melilla (29). Las que más bibliotecas han creado en esta

\begin{tabular}{|c|c|}
\hline Administrat:iixı c:terıltrial & 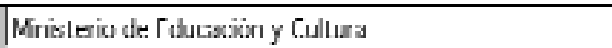 \\
\hline \multicolumn{2}{|c|}{$\begin{array}{l}\text { Uircccion Gcncral dcl Libro, Archivos y Bibliotocas } \\
\text { http://www.mcues/lab/index.html }\end{array}$} \\
\hline 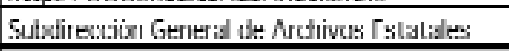 & 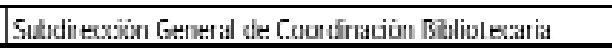 \\
\hline Arutalucia: & Corresyjentia de C.ulluria \\
\hline \multicolumn{2}{|c|}{ 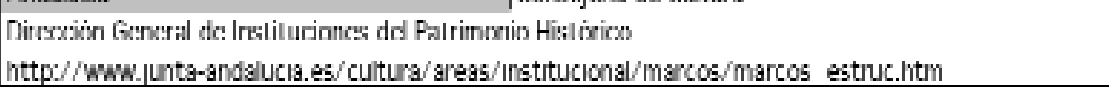 } \\
\hline Arctivu Gerierial in Arutslucia: & Fibfolencis de Muldalucis \\
\hline Arisgün & Deppar larreerto de Cultura y Turisano \\
\hline \multicolumn{2}{|l|}{ 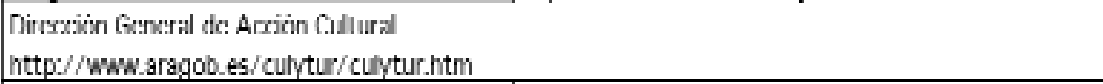 } \\
\hline Serrvicio de Mutivas y Museas & 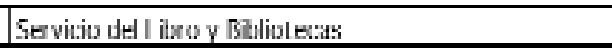 \\
\hline Aslurias & 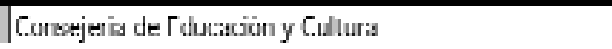 \\
\hline \multicolumn{2}{|l|}{ 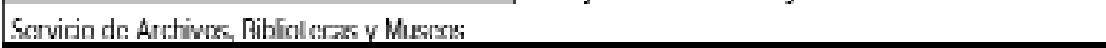 } \\
\hline Balcarcs & Conscicría de toucación. Cultura y ucportcs \\
\hline \multicolumn{2}{|l|}{$\begin{array}{l}\text { Direccion Ceneral de Cultura } \\
\text { Hup://www.ciab.ex/sacl.hin }\end{array}$} \\
\hline Camarias & 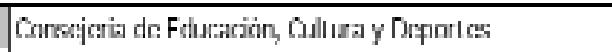 \\
\hline \multicolumn{2}{|l|}{ Uiraccion Gencral de Qultura } \\
\hline Cantabria & Conscicria de Cultura y Leportc \\
\hline \multicolumn{2}{|l|}{ 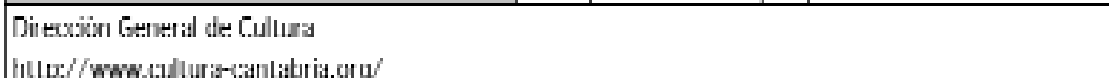 } \\
\hline Catilla I is Manx:ha & 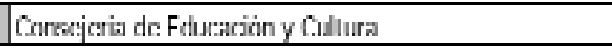 \\
\hline \multicolumn{2}{|c|}{ 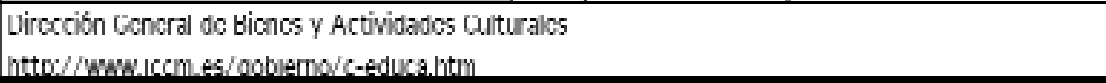 } \\
\hline Cossillts y I tün & 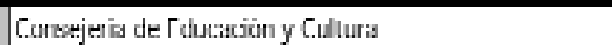 \\
\hline \multicolumn{2}{|c|}{ 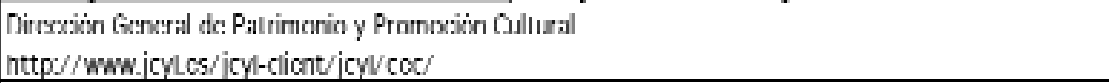 } \\
\hline \multicolumn{2}{|l|}{ 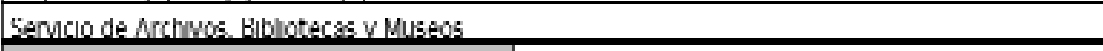 } \\
\hline Calisiluitis & Corresejentis de C.ulluris \\
\hline 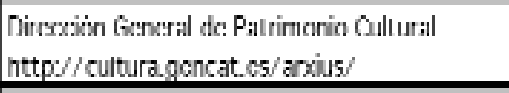 & 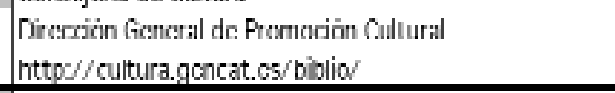 \\
\hline Ceuta & Conselenla de Loucacion Cultura y ueporte \\
\hline Lxtremadura & Conselenta de Cultura \\
\hline \multicolumn{2}{|c|}{ 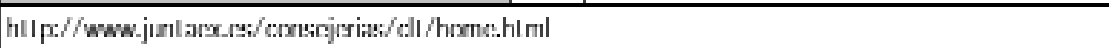 } \\
\hline Calicia & Conscicria de Cultura, Comunicación Social y I urismo \\
\hline \multicolumn{2}{|c|}{ http://www.xunta.es/consele/culturg//ndex.htm } \\
\hline 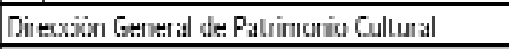 & Dir rexciün Getrental de Pronucuiün Culturial \\
\hline I * Rinjia & 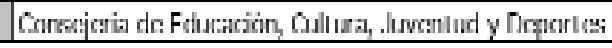 \\
\hline \multicolumn{2}{|c|}{ 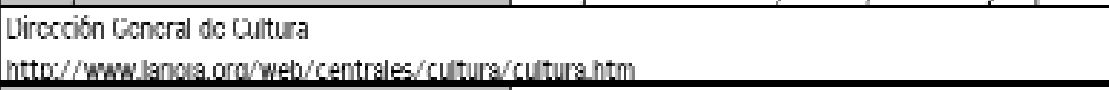 } \\
\hline Maudrid & 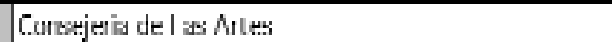 \\
\hline \multicolumn{2}{|c|}{ 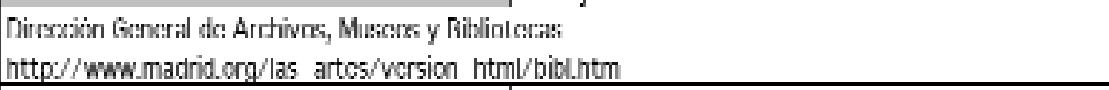 } \\
\hline Servicio Requonal de Nrchnos & Servicio lieglonal de Biblotecas y del Libro \\
\hline \multicolumn{2}{|l|}{ Melilis } \\
\hline Murcuis & 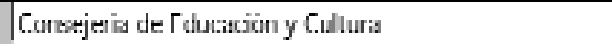 \\
\hline \multicolumn{2}{|c|}{ 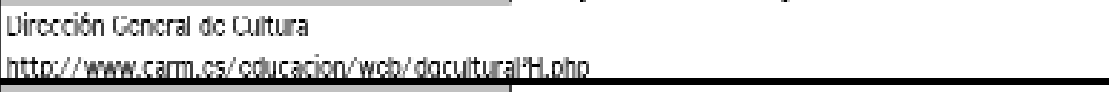 } \\
\hline Navarra & Consejenta de Loucación y Cultura \\
\hline \multicolumn{2}{|l|}{ 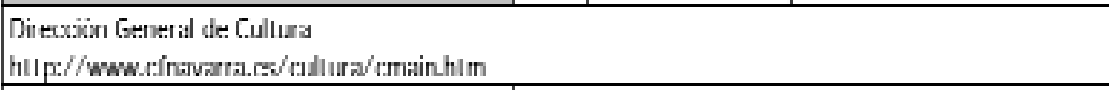 } \\
\hline Servicio de l'atnmonio l listònco & Servicio de Accion Cultural \\
\hline I'als Vesco & Conselerla de Cultura \\
\hline \multicolumn{2}{|c|}{ 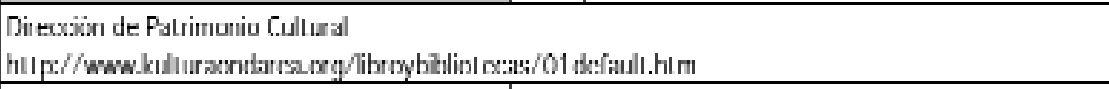 } \\
\hline Centro de l'atummonio Locumental de Luskadi & Servicio del Libro y Bollootecas \\
\hline Comunidad Valenciana & Consejenta de Cultura y Loucación \\
\hline
\end{tabular}

Cuadro 1. Órganos dependientes de la administración central y autonómica española responsables de la política bibliotecaria y documental. 
última década han sido por este orden: Canarias, Galicia, Extremadura, Baleares, Cataluña y Castilla La Mancha con tasas del crecimiento de $111 \%, 100 \%$, $80 \%, 68 \%, 67 \%$ y $50 \%$ respectivamente. Las que menos Navarra y Castilla y León. En algunas comunidades, el número de bibliotecas ha descendido (La Rioja y Cantabria).

Por su parte, según la estadística de archivos elaborada por el Cida (tabla 2) en España existían en el año 1998, 35.517 archivos, de los que la práctica totalidad son de carácter eclesiástico $(40 \%)$ o administrativo (38\%). A larga distancia de éstos se sitúan los pertenecientes a empresas (7\%). Dentro de la administración, el grupo más numeroso de archivos depende de la administración local (46\%) y de la de justicia (32\%).

Las comunidades autónomas con mayor número de archivos son: Castilla y León (8.579), Galicia (4.722), Andalucía (4.372), Comunidad Valenciana (3.523), Castilla La Mancha (3.505), Aragón (3.321), Navarra (2.223), Cataluña (1.922), Cantabria (1.049), Madrid (895), Asturias (714), La Rioja (755) y Canarias (122).

\section{«Las asociaciones profesiona- les y sociedades científicas son un indicador clave del gra- do de organización social de cualquier comunidad, sea cien- tífica o profesional»}

La parquedad de datos de la estadística de archivos impide ofrecer un retrato pormenorizado de los archivos españoles. Cataluña, que sí cuenta con unas estadísticas publicadas regularmente, ofrece información que, aunque difícilmente extrapolable, puede ser orientativa de la situación general. Los archivos catalanes son jóvenes (el 56\% se ha creado en los últimos 25 años) y de tamaño pequeño o mediano (el $45 \%$ tiene menos de 500 metros lineales de documentos).

\section{Los órganos de la administración bibliotecaria y documental}

La constitución de España como un estado de autonomías ha hecho que buena parte de las competencias relacionadas con el sector cultural, que es donde se incardinan los archivos y bibliotecas, haya sido transferida a las comunidades autónomas. Este proceso ha seguido distintos ritmos y grado de profundidad a lo largo de los años. Aunque también la administración local posee sus competencias al respecto, lo escaso del espacio de que dispongo impide hacer un análisis detallado de su entramado institucional. Ante todo, cabe resaltar la juventud de las estructuras administrativas que se han ido configurando en estos últimos 25 años. De la observación del cuadro 1, donde se relaciona el organigrama de la administración bibliotecaria y documental española, cabe destacar la reproducción con ligeros matices, sobre todo de carácter terminológico, del modelo organizativo imperante en la administración central:

-Adscripción al departamento de educación y cultura como órgano superior y, dentro de éste, al área de cultura.

-Separación, en un escalón inferior equivalente a una subdirección general o servicio, entre el mundo de los archivos y el de las bibliotecas.

-Diversidad terminológica. Sólo tres comunidades han mantenido, aunque con variaciones, la denominación de la centenaria Dirección General del Libro, Archivos y Bibliotecas: Madrid, Asturias y Comunidad Valenciana).

\section{La profesión}

\section{El colectivo profesional.}

Antes de comentar los datos, conviene recordar que se carece de información respecto al personal que trabaja en archivos y, en general, en el sector documental privado.

En el conjunto de las bibliotecas españolas hay empleado un total de 22.855 personas, de las que el $34 \%$ lo hacen en bibliotecas públicas generales, el $27 \%$ en bibliotecas de instituciones de enseñanza superior y el $22 \%$ en especializadas. El promedio de trabajadores por centro es de tres. Exceptuando la Biblioteca Nacional y otras importantes no especializadas, son las bibliotecas universitarias las que cuentan con más personal (11 de promedio) mientras que las públicas las que menos (2 trabajadores). El crecimiento del personal bibliotecario en esta última década ha sido considerable: en equivalencia a dedicación plena se ha pasado de 11.001 trabajadores en 1990 a 17.786 en 2000, lo que significa un crecimiento del $62 \%$.

Las comunidades autónomas con mayor número de trabajadores son: Madrid (5.031), Cataluña (3.238), Andalucía (2.980), Comunidad Valenciana (1.780), Galicia (1.673), Castilla y León (1.578), País Vasco (1.148), Castilla La Mancha (1.078), Extremadura (820), Aragón (771), Canarias (715), Murcia (522), Asturias (394), Navarra (360), Baleares (357), Cantabria (205) y La Rioja (133).

En cuanto a la dedicación, señalar que el $65 \%$ del personal trabaja con dedicación plena (14.856) (tabla 3). Son de nuevo la Biblioteca Nacional, otras importantes no especializadas y las bibliotecas universitarias las que emplean más personal a tiempo completo $(95 \%$ y $83 \%$ ). De igual manera son las públicas las que me- 


\begin{tabular}{|c|c|c|c|c|c|c|c|c|}
\hline & \multirow{3}{*}{$\begin{array}{l}\text { Torel porsonel } \\
\text { bibliotecsas }\end{array}$} & \multirow{2}{*}{\multicolumn{2}{|c|}{ Ledicación }} & \multicolumn{5}{|c|}{ Fanmacisn } \\
\hline & & & & \multirow{2}{*}{ 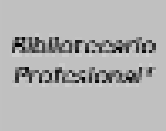 } & \multicolumn{3}{|c|}{ bubiotecario formado"t } & \multirow{2}{*}{ Utro personal } \\
\hline & & Hicna & Parcial & & Uecenciado $\triangle$ dacto & Lpiomado & $\begin{array}{l}\text { Sn titulacibn } \\
\text { Lrivergitaris }\end{array}$ & \\
\hline Total & 22.855 & 11.856 & 7.999 & 5.010 & 3.610 & 1.993 & 1.578 & 7.631 \\
\hline Nocionsles & 161 & 163 & 1 & 129 & 0 & 0 & 11 & 321 \\
\hline $\begin{array}{l}\text { Otras importantes } \\
\text { no especializadse }\end{array}$ & $1.9 / 4$ & 1...900 & $1 / 4$ & S10. & 133 & $10 \%$ & 351 & $8 / 8$ \\
\hline Públoses & 9.192 & $1.46 B$ & 1.721 & 1.256 & 1.163 & 1.003 & 2.359 & 3.111 \\
\hline Genterales & 7.657 & 1.002 & 3.655 & 1.164 & 1.288 & 819 & 1.963 & 2.393 \\
\hline De organismos militares & 532 & 200 & 332 & 28 & 61 & 31 & 122 & 287 \\
\hline $\begin{array}{l}\text { De horpitales } \\
\text { (no expeoslzadus) }\end{array}$ & 91 & 37 & 54 & 13 & 10 & 9 & 29 & 30 \\
\hline $\begin{array}{l}\text { De institudoones } \\
\text { perrilenciarias }\end{array}$ & 213 & 19 & 161 & 8 & 16 & 36 & 11 & 112 \\
\hline De colengio mayor & 382 & 34 & 348 & 9 & 28 & 38 & 152 & 155 \\
\hline Otrass puiblitars & 317 & 146 & 171 & 34 & 57 & 40 & 82 & 104 \\
\hline frstútuciones de & 6.184 & 5.026 & 1.158 & 2026 & 820 & 376 & 915 & 2.047 \\
\hline 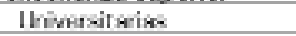 & 5.767 & 4.935 & 1.077 & 1.999 & 753 & 375 & 878 & 2007 \\
\hline No wivntsitseise & 777 & 91 & 131 & 77 & 67 & 51 & 37 & 40 \\
\hline Fxywxixizadhe & 5.041 & 3099 & $1.94 ?$ & 1.094 & 1.274 & 507 & 939 & 1277 \\
\hline Fudiginate & 408 & 120 & 288 & 50 & 161 & 38 & 87 & 72 \\
\hline 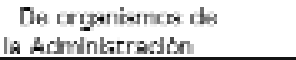 & 799 & 634 & 165 & 184 & 135 & 67 & 145 & 268 \\
\hline $\begin{array}{l}\text { De comtrat de } \\
\text { investloasion }\end{array}$ & 663 & 523 & 140 & 145 & 140 & 74 & 181 & 123 \\
\hline 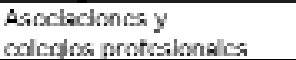 & 586 & 177 & 414 & 73 & 155 & 41 & 108 & 709 \\
\hline We empresia & 341 & $2 \widehat{3.3}$ & $A B$ & 749 & 6.3 & 9 & 34 & 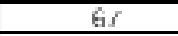 \\
\hline Ue archivog y muacog & $59: 8$ & $2 \mathrm{Bf}$ & 309 & $74 /$ & $15 !$ & $3 ! s$ & 8.3 & 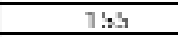 \\
\hline Utrez capccializadaa & 1.64 .9 & 1.091 & 3694 & $34 /$ & $41: 5$ & 223 & 281 & $3 \mathrm{BB3}$ \\
\hline
\end{tabular}

Tabla 3. Personal al servicio de las bibliotecas en España según tipo de biblioteca, dedicación y formación en 2000.

Fuente: Instituto Nacional de Estadística. Estadística de bibliotecas 2000.

* Se refiere a los profesionales con título acreditativo, es decir: los pertenecientes a los cuerpos de facultativos y ayudantes de archivos y bibliotecas, de archiveros y bibliotecarios de comunidades autónomas, de archiveros y bibliotecarios de ayuntamientos 0 auxiliares de biblioteca de universidad y los que tengan realizados los cursos de documentalistas o sean diplomados en biblioteconomía.

** Bibliotecarios formados en el ejercicio de sus funciones: los que teniendo una formación general en biblioteconomía o en ciencias de la información adquirida en el ejercicio de su actividad diaria, no están respaldados por un título acreditativo.

nos empleados poseen con dedicación plena, ya que la mitad de sus trabajadores están contratados a tiempo parcial. Las que presentan mayor precariedad son las bibliotecas de asociaciones profesionales, las de organismos militares y las de instituciones penitenciarias. Por comunidades autónomas, donde trabajan más bibliotecarios con dedicación plena es en Madrid y Cantabria (76\%), Cataluña (71\%) y Asturias (70\%), y donde menos en Extremadura (36\%), Castilla La Mancha (42\%), Aragón (52\%), Baleares y Galicia (56\%).

\section{«Se puede estimar que las aso- ciaciones representan no más de un cuarto de los profesiona- les en ejercicio»}

En cuanto a la formación, la mayoría de los bibliotecarios se preparan en el ejercicio de sus funciones en la biblioteca (45\%); de entre ellos más de la mitad poseen titulación universitaria (tabla 3), aunque sólo el $22 \%$ son bibliotecarios profesionales (5.010), es decir, trabajadores que posean título acreditativo. Donde mayor proporción de este personal hay es en las bibliotecas universitarias (33\%) y en las empresas (43\%), y en donde menos en las bibliotecas públicas (14\%). Por comunidades autónomas donde más bibliotecarios profesionales existen es en Cantabria (38\%), Cataluña (34\%), Asturias (32\%) y La Rioja (35\%) y donde menos en Extremadura (8\%), Comunidad Valenciana (9\%) Aragón (12\%) y País Vasco (13\%).

\section{Asociaciones profesionales y sociedades cien- tíficas.}

Son los principales medios de vertebración interna y externa con que cuenta cualquier comunidad para hacerse presente en la sociedad. Dotan de identidad social a un colectivo profesional, fijan normas que rigen su vida (acceso, ejercicio y desarrollo profesional) y defienden sus intereses corporativos. Surgen cuando la práctica profesional está suficientemente consolidada, esto es, cuando existe una masa crítica de profesionales suficiente y cuando se hace patente una conciencia social de grupo. Son un indicador clave del grado de organización social de cualquier comunidad, sea científica o profesional.

En la actualidad existen en nuestro país 31 organizaciones ligadas a nuestro campo de conocimiento (cuadro 2). El retrato robot de nuestras asociaciones es el que sigue: 


\begin{tabular}{|c|c|}
\hline Asociaciones professionales y socicdades cicntificas & Dirccción electrónica \\
\hline Asociación Andaluza de Archiveros (AAA) & http://www.sopde.es/organismos/aas/inicio.htmlitcuatrol \\
\hline Asociación Andaluza de Bibliotecarios (AAB) & htto://www.aab.es \\
\hline Asociación Andaluza de Documentalistas (AAD) & htto://www.aadocumentalistas.org/ \\
\hline $\begin{array}{l}\text { Asociación Asturiana de Bibliotecarios, Archiveros, } \\
\text { Decumentalistas y Musedocoss (Aabadom) }\end{array}$ & hiltp://www.alatbactern.corg \\
\hline \multicolumn{2}{|l|}{$\begin{array}{l}\text { Asociación Asturiana por las Bibliotocas Escolares } \\
\text { y la__ectura (Aabel) }\end{array}$} \\
\hline Asociación Bibliotccaria Galcog (ABG) & http://www.spid.cs/wcbs/abg/ \\
\hline \multicolumn{2}{|l|}{$\begin{array}{l}\text { Asnciación Canaria de Archiveros, Bibliotecarics } \\
\text { y Donumentalistals (Ar.abd) }\end{array}$} \\
\hline \multicolumn{2}{|l|}{ 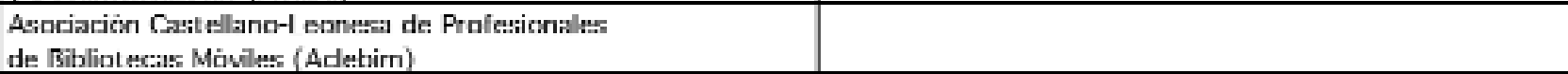 } \\
\hline \multicolumn{2}{|l|}{ Astaciaricion de Archiveras de Cussilla y I ean (Acal) } \\
\hline \multicolumn{2}{|l|}{ Asociación de Archiveros de la Iglesia en Esparîa (Aaie) } \\
\hline \multicolumn{2}{|l|}{ 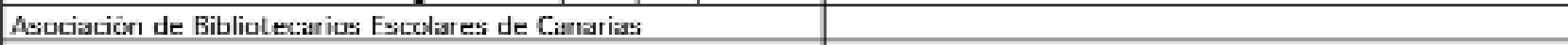 } \\
\hline \multicolumn{2}{|l|}{ Asociación de Bibliotecarios tscolares txtremefios } \\
\hline $\begin{array}{l}\text { Asociación de Bibliotecarios y Bibliotecas } \\
\text { de Arquitectura. Construcción y Urbanismo }\end{array}$ & http://www,cschcr,upccs/bib210/abba/abba.htm \\
\hline \multicolumn{2}{|l|}{$\begin{array}{l}\text { Asociación de Bibliotecarios, Archiveros, } \\
\text { Documentalistas y Museoblogos de Extremadura (Abadmex) }\end{array}$} \\
\hline Asociación Espaniola de Documentación Musical (Aedom) & htto://www.rayuela.uc3m.es/--ignatius/publica.html \\
\hline $\begin{array}{l}\text { Asociación Galega polas Bibliotecas Escolarcs } \\
\text { ca Lectura (Agabcl) }\end{array}$ & http://www.sgatbel(00.tripod.com/horre.htm \\
\hline Asociación Hispana de Documentalistas en Intemet (Ahdi) & http://www,documentalistas,com \\
\hline 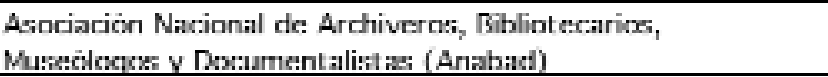 & http://www.anabad.org/ \\
\hline \multicolumn{2}{|l|}{ 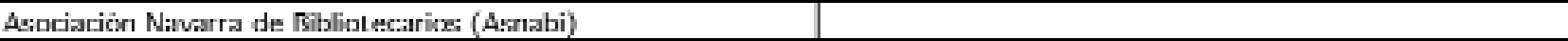 } \\
\hline \multicolumn{2}{|l|}{ 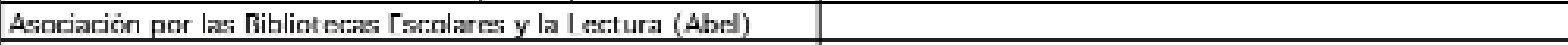 } \\
\hline 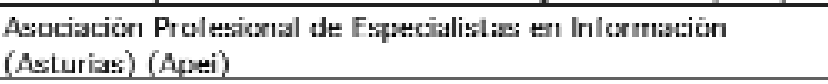 & http://www.apei.org/index.htm \\
\hline \multicolumn{2}{|l|}{ Asuciascioún Valenciana de Especialistas en Información (Avei) } \\
\hline $\begin{array}{l}\text { Asociación Vasca de blbliotecarios, Mrchiveros, } \\
\text { Documentalistas (Adee) }\end{array}$ & http://www.fosabid_org/aldec/ \\
\hline Associació d'Arxivers de Catalunya (AAC) & http://www.aroivers.com \\
\hline Associació d'Arxivers Valencians (AAV) & htto://www.arxiversvalencians.org/ \\
\hline Associació de Bibliotecaris Valencians (ABV) & htto://www.llibroweb.com/abv/ \\
\hline $\begin{array}{l}\text { Associació de Bibliotecaris, Arxivers i Documentalistes } \\
\text { de les lles Balears (Abadib) }\end{array}$ & http://www.sbadib.es/ \\
\hline $\begin{array}{l}\text { Capitulo espaniol do Isko (International Society } \\
\text { Knowlodoc Oroanization) }\end{array}$ & http://www.ugr.es/--isko \\
\hline Col.lcgi Oficial de Bibliotccaris-Documcntalistes de Catalunya & htto://www.cobdcorg/ \\
\hline 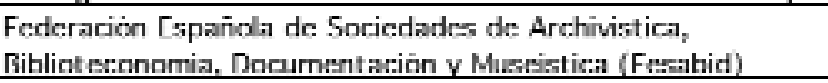 & http://www.fesabid_org/ \\
\hline 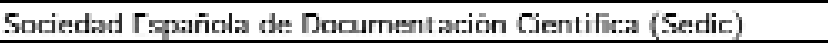 & http://www.sneclic.en:/ \\
\hline Sociediad Fspariola de Documentiación Mèdica (Sedom) & |http://www.uv.es/ /docried/sediorn/seddorn.html \\
\hline
\end{tabular}

- Se trata de entidades muy jóvenes: sólo dos (Anabad y Sedic) superan los cinco lustros de vida. En la década de los ochenta es cuando nacen las principales entidades profesionales, pero será en los noventa cuando proliferen (el 66\% de las organizaciones se crea durante esos años).

-El $80 \%$ son corporaciones profesionales, esto es, grupos creados con la primaria finalidad de defender los intereses profesionales de sus asociados ante cualquier instancia social. El resto son sociedades científicas, más bien dirigidas a acotar espacios y especialidades del saber donde compartir experiencias y conocimientos.
-Predominan claramente las entidades especializadas por ramas profesionales y especialidades $(80 \%)$ frente a las generales (Anabad, Aabadom, Abadmex, Aldee, Abadib, Acabd), que agrupan en su seno a las tres ramas en que históricamente se ha segmentado nuestra profesión (archiveros, bibliotecarios y documentalistas). Por ramas profesionales el sector con mayor número de organizaciones es el bibliotecario con 12, de las cuales cuatro agrupan a los profesionales de toda una región (Andalucía, Comunidad Valenciana, Galicia, Navarra), cinco están especializadas en el campo de las bibliotecas escolares (Asturias, Canarias, Extremadura, Galicia, Madrid), una en bibliotecas móviles y una en arquitectura. Las otras dos ramas de 
Las cifras de la documentación en España: 2002

\begin{tabular}{|c|c|c|c|c|c|}
\hline 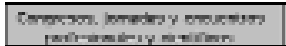 & ir at mavornat & orghower & 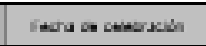 & usr at insinole & craccíl wacrice \\
\hline \multicolumn{6}{|c|}{ कासे } \\
\hline 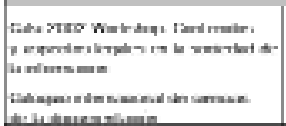 & J & 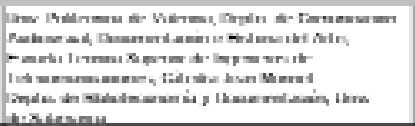 & $\begin{array}{l}22-25 \text { sctibn } 2002 \\
11-15 \text { movertion } 2008\end{array}$ & Velonti: & 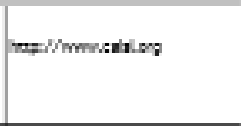 \\
\hline Corovers de in dostiketion do & is & 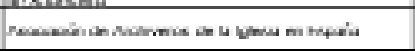 & 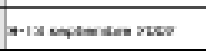 & 1Semen & \\
\hline 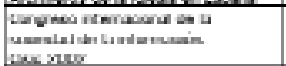 & , & 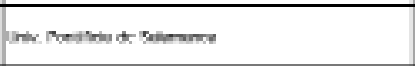 & 27 notron 1 man sone & Setomenter & 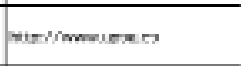 \\
\hline 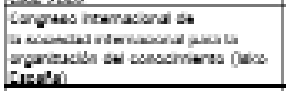 & 7 & 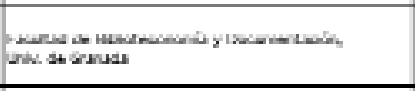 & 90.1514002002 & Orenter & 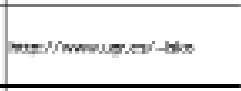 \\
\hline 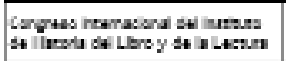 & 1 & 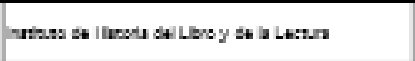 & 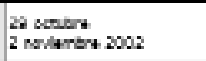 & Sarrarea & \multirow{3}{*}{ 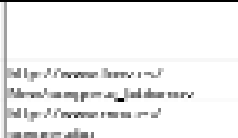 } \\
\hline $\lim _{x \rightarrow \infty}$ & 1 & 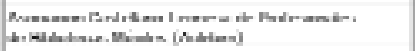 & $12 \cdot 20$ serrabre 2002 & Sapova & \\
\hline 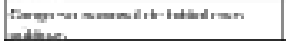 & 1 & 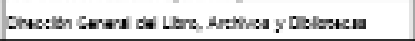 & 22.21 actaber 2000 & Valenca & \\
\hline 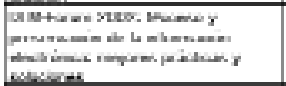 & & 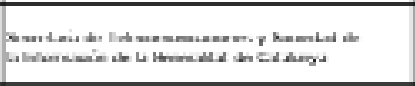 & QD- ravo 2002 & Dredion & 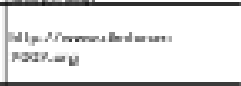 \\
\hline 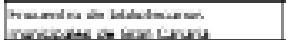 & 4 & 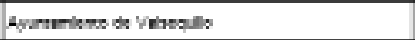 & $17-m e s-08$ & Oren Convits & \\
\hline 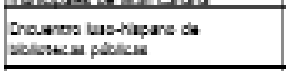 & s & 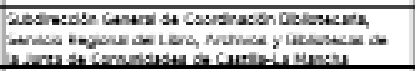 & 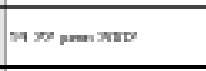 & 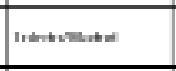 & \\
\hline 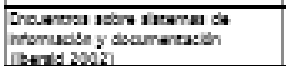 & $r$ & 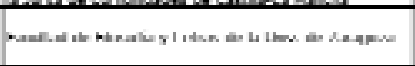 & A a mentien Ptro & Caspus & 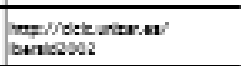 \\
\hline 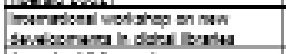 & ? & 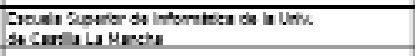 & $7 \times$ den Yus & Denter thed & 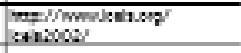 \\
\hline Jornian biblencerin & 10 & 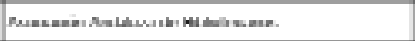 & No:n =upastave & mises & 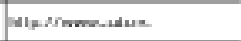 \\
\hline 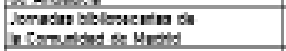 & $\therefore$ & 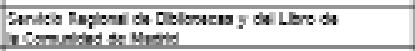 & A - 111 madan Xtes & Webuid & \\
\hline 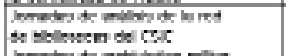 & ; & 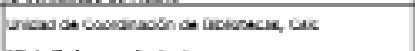 & anes was esai & meand & \\
\hline 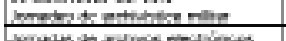 & + & 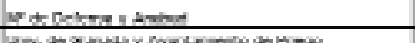 & Is 17 teal 2000 & Woted & \multirow{4}{*}{ 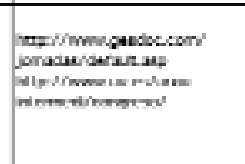 } \\
\hline 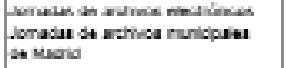 & $\stackrel{2}{14}$ & 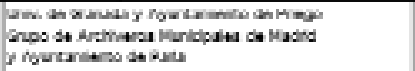 & 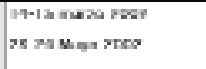 & Simenten & \\
\hline Jorasin de Erahica univerizarioa & 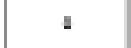 & 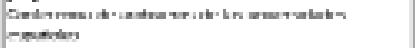 & $12 \cdot 14$ junle 2002 & Valenca & \\
\hline 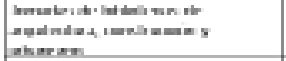 & 12 & 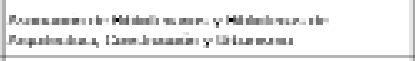 & $10 \cdot 20$ sctabre 2002 & Maskd & \\
\hline 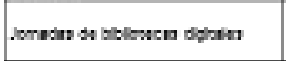 & J & 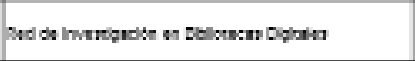 & $19-25$ movertion 2008 & Watrd & 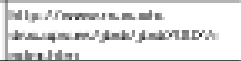 \\
\hline Joreding de blalowen exsina & 2 & 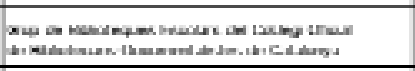 & 14.18 fithere 2008 & Dercolone & 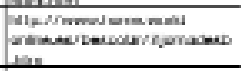 \\
\hline 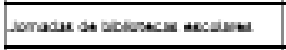 & z & 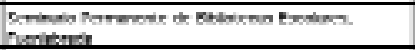 & casponact & ievand & 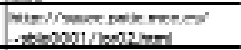 \\
\hline 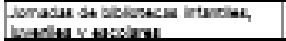 & 10 & 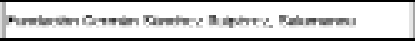 & 27 ก & ratiments & 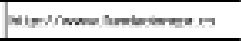 \\
\hline 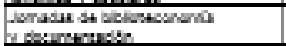 & 11 & 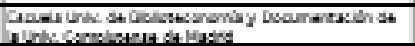 & 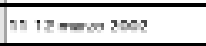 & Wenter & 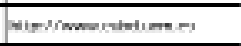 \\
\hline 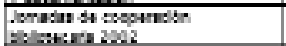 & 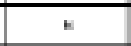 & 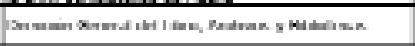 & 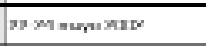 & 16.entemen: & \\
\hline 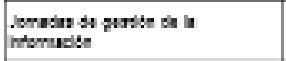 & 1 & 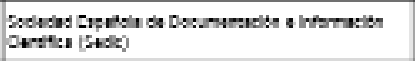 & Novi amomaten ntes & Menat & 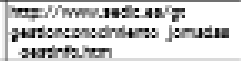 \\
\hline 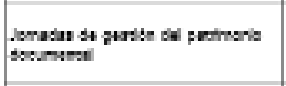 & - & 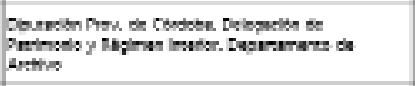 & Ns sei madan yteo & Dambata & 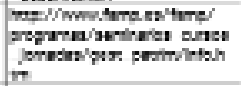 \\
\hline 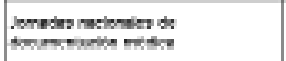 & is & 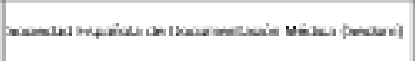 & 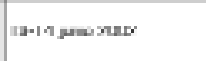 & wewat & moilimmusces' \\
\hline 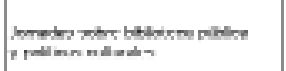 & 4 & 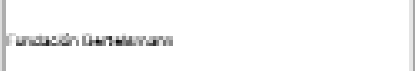 & 14.15 ectave itev & aucenosa & 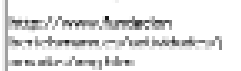 \\
\hline 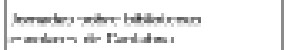 & 1 & 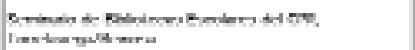 & I.2 nuas ases & Enera & \\
\hline 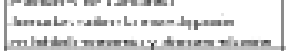 & 2 & 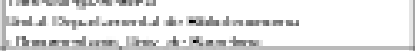 & $12 \cdot \operatorname{sen} 02$ & Drewern & 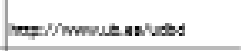 \\
\hline 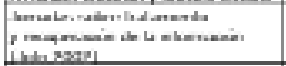 & 1 & 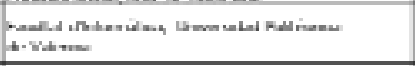 & 4-5 julo 2002 & Vilonti: & 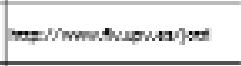 \\
\hline 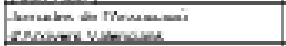 & 2 & 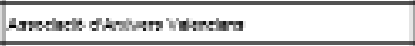 & 1n-12 sciemore 2000 & Vulonch & 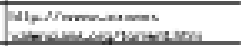 \\
\hline 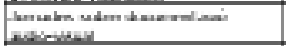 & 1 & 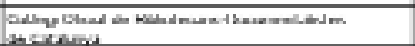 & S-mentos & Dercelon! & \\
\hline 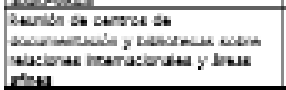 & , & 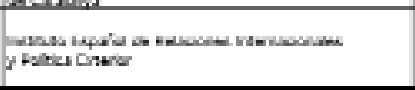 & didentere 2000 & & \\
\hline 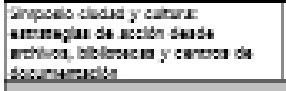 & . & 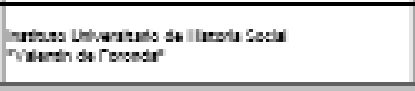 & Is phases ytes & vasur. & 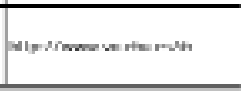 \\
\hline \multicolumn{6}{|c|}{ 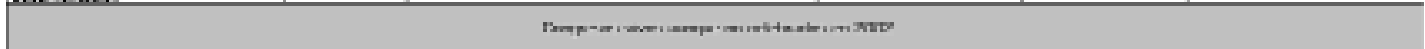 } \\
\hline 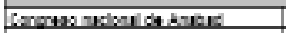 & 7 & Gortad & inditim & Tokito & \\
\hline 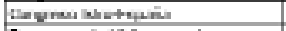 & b & 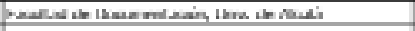 & 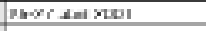 & Navimite & \\
\hline Prownon so bellow:n do are & * & 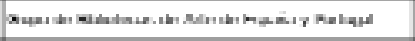 & 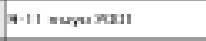 & Medrenak. & \\
\hline 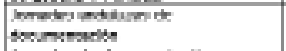 & a & 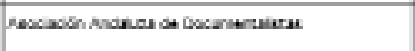 & $\omega \infty$ & Grasas & 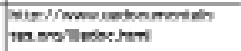 \\
\hline 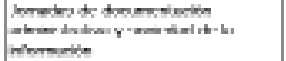 & & 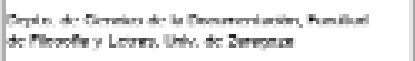 & $22 \cdot 24$ actabs 2061 & Irsogas & 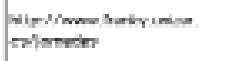 \\
\hline 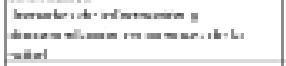 & 2 & ade & 24-26 noveritere 2001 & Casen & \\
\hline 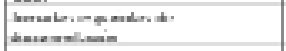 & 7 & ranst & $12 \cdot 21$ sertabre 2000 & biens & 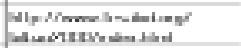 \\
\hline 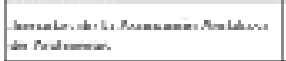 & J & 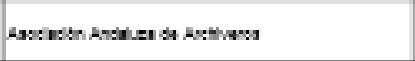 & $n 0460$ & Condot: & 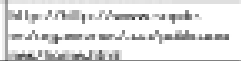 \\
\hline 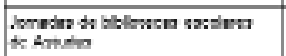 & 1 & 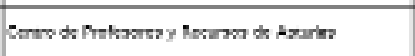 & 5.7 septention 2001 & Outedo & 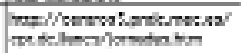 \\
\hline 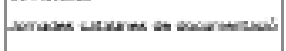 & • & 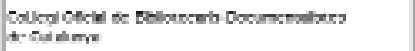 & 15.16 averaces sevi & Iunceses & 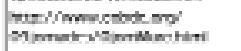 \\
\hline 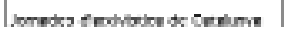 & ? & 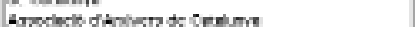 & 17.12 rems 2001 & Tomen & \\
\hline
\end{tabular}

Cuadro 3. Congresos, jornadas y encuentros profesionales y científicos celebrados en España sobre archivística, biblioteconomía y documentación. Fuente: elaboración propia. 


\begin{tabular}{|c|c|c|c|c|c|c|}
\hline Univesidad & Concro & Direcekin clectrúnica. & Dielomatura & Lecerciatura & Doctarsdo & Depertimente \\
\hline A. Limútax & 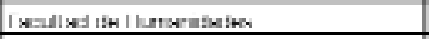 & 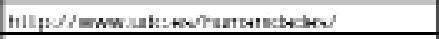 & $x$ & & & 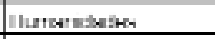 \\
\hline Alazls de Horeres & Fosultad de Documcertacion & 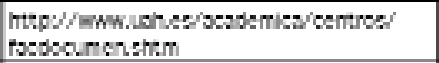 & & $x$ & $x$ & $\begin{array}{l}\text { Oencias sanitarivs } \\
\text { y modico socialss }\end{array}$ \\
\hline & Focultad de Oencise de la Comunicarion & 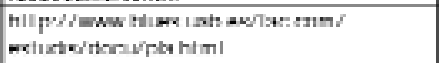 & & $x$ & $x$ & Fiologla cetalano \\
\hline Berocions & 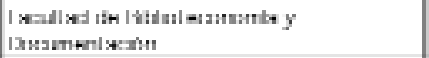 & Ittp://mww.ub.es/blblor & $x$ & $x$ & $x$ & 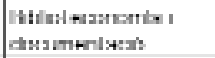 \\
\hline Costow Il das Motril & 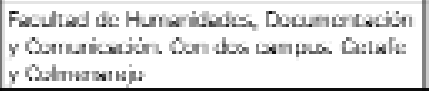 & 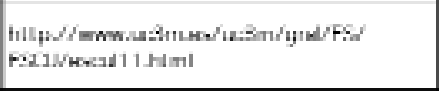 & $x$ & $\mathrm{x}$ & $x$ & 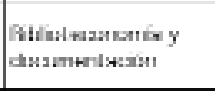 \\
\hline Compluterse de Madro & 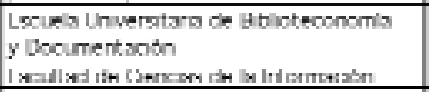 & 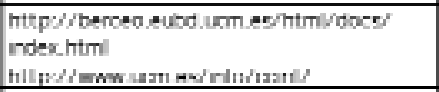 & $x$ & $x$ & $x$ & $\begin{array}{l}\text { Abioteconomis y } \\
\text { documentacion }\end{array}$ \\
\hline rxiranseluex & $\begin{array}{l}\text { Focultod de Blbllotcconomla y } \\
\text { Docungroglon }\end{array}$ & 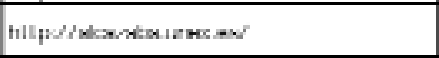 & $x$ & $x$ & $x$ & intermbl nat \\
\hline Vinserate & $\begin{array}{l}\text { Focultad de Blblloteconomla y } \\
\text { Documanteakn }\end{array}$ & hillp//mww ung mo/-ltas/ & $x$ & $x$ & $x$ & 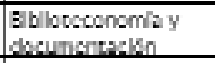 \\
\hline Loón & Foculad de Flosafia y Letric & 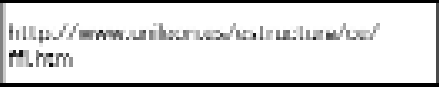 & $x$ & & & 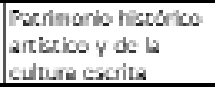 \\
\hline Muncle & Fisulad de Oenclia de la Documercacion & 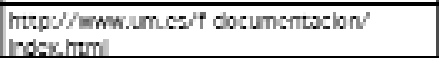 & $x$ & $\mathrm{x}$ & $x$ & $\begin{array}{l}\text { informiscldny } \\
\text { chocumartakikn }\end{array}$ \\
\hline Cliser lx dis Malstanys & & 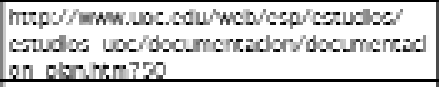 & & $x$ & & \\
\hline 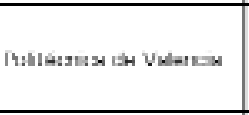 & I weallixed Ifw Informal ax & hillp $/ /$ mww. In. & & $x$ & & 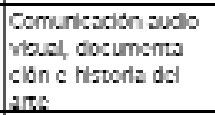 \\
\hline titbertartsa & 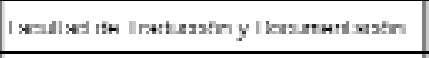 & hilplinocikar unod new & $x$ & $x$ & & $\begin{array}{l}\text { By blotcconomis y } \\
\text { docungertyking }\end{array}$ \\
\hline Valenco Letudi Generd & racultad de Geogrthe e Hetons & Ittp://mww.un.eg/geohst/ & $x$ & & $x$ & $\begin{array}{l}\text { Hetoria of is oencia } \\
\text { y documentsoldon }\end{array}$ \\
\hline$v=$ & 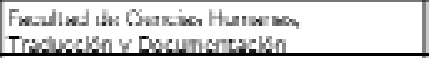 & hilip/imww uns: mo/lthils: & $x$ & & & $\begin{array}{l}\text { Informatis i } \\
\text { cheuncroves }\end{array}$ \\
\hline $2 x \operatorname{soc} 28$ & Foculiad de Flosofia y Letrec & hrtp:J/Pluriasices & $x$ & & $x$ & 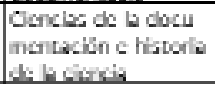 \\
\hline
\end{tabular}

Cuadro 4. Centros universitarios españoles donde se imparten enseñanzas regladas en ciencias de la documentación. Fuente: elaboración propia.

la profesión cuentan con 9 asociaciones, cinco los archiveros (AAA, AAC, AAV, Acal, Aaie) y cuatro los documentalistas (Sedic, Aad, Apei, Avei).

-Atendiendo al ámbito geográfico, predominan las asociaciones de carácter regional $(75 \%)$ sobre las nacionales. Cinco regiones carecen de organizaciones propias (Aragón, Murcia, Castilla La Mancha, Cantabria, La Rioja). El motivo no es otro que sus profesionales se encuentran inscritos en asociaciones nacionales, como es el caso de Aragón, Murcia y Castilla La Mancha, que cuentan con secciones territoriales autónomas dentro de Anabad. Por el contrario, las regiones con mayor número de asociaciones son Andalucía, Comunidad Valenciana, Asturias y Cataluña que, con excepciones que comentaré a continuación, son las zonas con una infraestructura documental de mayor tamaño y con colectivos profesionales más numerosos. El caso de Madrid requiere comentario aparte. Esta comunidad no ha generado asociaciones propias porque tanto la Sedic como Anabad, a pesar de tener ámbito nacional, por radicar en Madrid han atraído desde su origen a los profesionales madrileños, que son mayoría en su seno. El caso asturiano es más paradójico, dado que es una comunidad con pocos profesionales y una infraestructura documental menuda.

- La multiplicación de sociedades hizo necesario, ya en los ochenta, la creación de una entidad que pu- diera, a nivel nacional defender los intereses comunes a todas las profesiones documentales. Así nace Fesabid en 1988. Es una federación que, aunque abraza en su seno a menos de la mitad de las asociaciones existentes (Aldee, AAB, AAD, Aabadom, Abadmex, Aedom, Anabad, Asnabi, Abadib, Avei, Cobdc, Sedic), representa a las de mayor antigüedad, tamaño y actividad. No obstante, se advierte que el sector archivístico es el peor representado, ya que a pesar de la presencia de Anabad, Aabadom, Aldee y Abadmex, en donde militan archiveros, ninguna de las cinco asociaciones regionales de archiveros están en Fesabid.

\section{«Los programas de doctorado se caracterizan por su falta de homogeneidad interna y espe- cialización definida, a pesar de lo que pudiera pensarse al ho- jear sus títulos»}

- Por problemas de tiempo no he podido reunir datos del número de socios que están afiliados a las 30 organizaciones existentes. De la información que dispongo se desprende que son a la limón el Cobdc catalán con 1.728 socios y la Anabad con 1.700 las asociaciones de mayor tamaño, seguidas por Sedic (1.122), AAC (700), AAB (505), Aldee (350), AAA (200), $A A D$ (185), Sedom (200). Haciendo una pro- 
yección de estos datos, cálculo bastante arriesgado por otra parte, se puede estimar que las asociaciones representan no más de un cuarto de los profesionales en ejercicio. Las tasas son bajas pero coincidentes con el bajo grado de asociacionismo existente en España a todos los niveles. La excepción está en Cataluña donde el Cobdc vendría a significar casi la mitad del colectivo bibliotecario catalán, y la $A A C$ superaría la barrera del $70 \%$. Por el contrario, la $A A B$ sólo cubriría al $17 \%$ del colectivo bibliotecario andaluz.

\section{Congresos, jornadas y encuentros profesiona- les y científicos.}

Constituyen una pieza fundamental para la articulación de una profesión o disciplina. Como foro de reunión que son, sirven ante todo para fomentar las relaciones personales, aumentar el conocimiento mutuo, entablar relaciones directas entre compañeros, compartir creencias y establecer valores comunes; en definitiva, actúan como un elemento vertebrador del grupo social. Asimismo, cumplen la función de coadyuvar al enriquecimiento profesional y científico de los asistentes, que extraen y aprenden experiencias que pueden poner en práctica en sus entornos y realidades. Pero, además, actúan como cauces de comunicación y expresión científica y profesional, trasladando ideas, nuevos conocimientos y descubrimientos científicos. Este papel de vehículos de información es especialmente importante en las profesiones o disciplinas con un bajo grado de institucionalización social, cual es el caso de España.

En 2002 se celebraron en España 38 congresos o jornadas profesionales o científicas en el campo de la documentación (cuadro 3). Contrasta poderosamente esta situación con la de hace 25 años cuando apenas si se celebraba uno. Los principales rasgos de los eventos llevados a cabo son los siguientes:

- La juventud es el primer punto a destacar. Hay que esperar hasta la década de los ochenta para que comiencen a celebrarse los primeros congresos de la profesión; el único existente hasta ese momento era el Congreso nacional de Anabad, que se remonta en su primera edición al año 1950. Son precisamente los congresos surgidos en esa época los que congregan mayor número de asistentes y los que tienen mayor impacto en la profesión (Jornadas españolas de documentación, andaluzas y catalanas). Ahora bien, es en los últimos años de los noventa cuando se desata una auténtica furia organizadora.

- Los principales patrocinadores de los congresos son las asociaciones profesionales y las universidades, que organizan la mitad de ellos, seguidos de la administración bibliotecaria y documental.

-Predominan claramente los encuentros de carácter nacional (23), sobre los de ámbito regional (10) o internacional (5).

-Atendiendo a la temática de los congresos, sobresalen los destinados a aspectos relacionados con las bibliotecas y sus servicios (50\%). Dentro de ellos constituyen un grupo bien diferenciado los dedicados a bibliotecas escolares. Son ya numerosos los celebrados dentro del mundo de la archivística (15\%) y a la tecnología de la información (15\%). Cabe comentar por su especial relevancia los congresos patrocinados por las asociaciones profesionales que tienen un alcance general en tanto que tratan de todas las cuestiones relativas a la profesión, a la gestión de las unidades do-

\begin{tabular}{|c|c|c|c|}
\hline Tltulo programa de doctorsdo & Unthersldsd & Deportamento & Direccion electronics \\
\hline 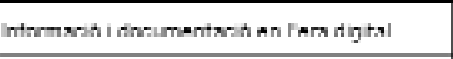 & 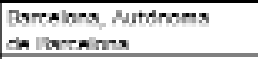 & 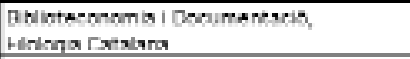 & 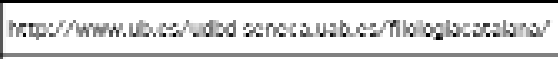 \\
\hline Iknamaritaratin & CSaricax II & 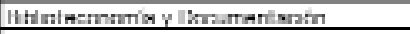 & 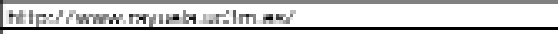 \\
\hline 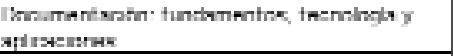 & \multirow{2}{*}{ Complustenes do Motind } & Bblloteconomils y Documensolon & netp $/ /$ www.ucm.es/info/multidoc/ \\
\hline 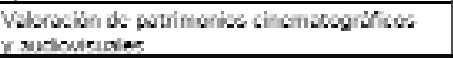 & & 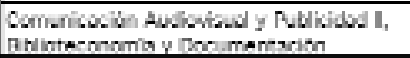 & \\
\hline 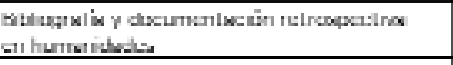 & 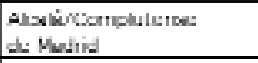 & |iningix | equatinls $N$ & \\
\hline 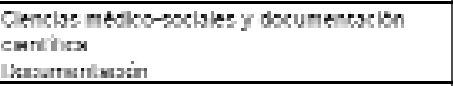 & \begin{tabular}{|l} 
Alcul \\
tolitumatury \\
\end{tabular} & 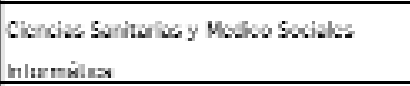 & \\
\hline Documentscion e informscibn cientifics & Orutrabu & 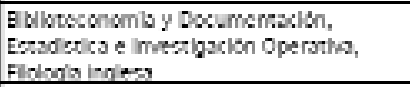 & \\
\hline 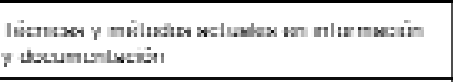 & 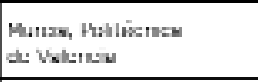 & 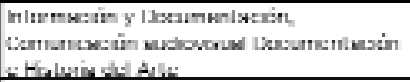 & 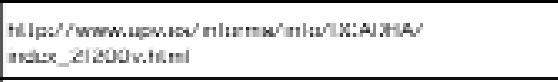 \\
\hline 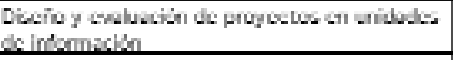 & Munise & Inlar mw:ain y I lecumunl wexin & 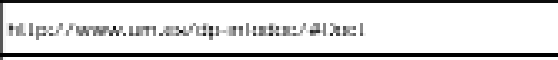 \\
\hline 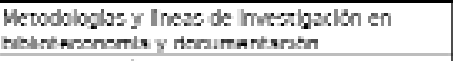 & Subatiutax & Buliulssunumiv y Dusanstivaiun & \\
\hline Iknamarlinatin & Volanes & 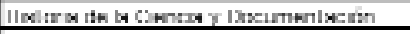 & 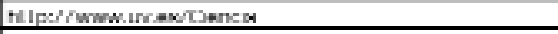 \\
\hline Skatema de infomscibny documenescion & Larstrom & 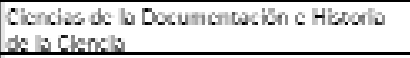 & \\
\hline Pstrimonio histbrico-sristico y documents & Leon & 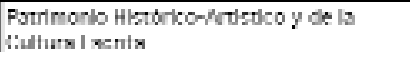 & hetp $/ /$ www 3. unleon es/dp/sbd/ \\
\hline
\end{tabular}

Cuadro 5. Programas españoles de doctorado en ciencias de la documentación. Fuente: elaboración propia. 
cumentales, a las técnicas de almacenamiento y recuperación y a la prestación de sus servicios.

-Atendiendo al lugar de celebración, es Madrid donde se llevan a cabo más eventos (9) seguido de Cataluña, Andalucía, Comunidad Valenciana y Castilla y León, las comunidades que cuentan con los colectivos profesionales de mayor tamaño (cuadro 3).

\section{La educación}

En este apartado nos referiremos exclusivamente a la formación universitaria reglada (primer, segundo y tercer ciclo), esto es, aquella que conduce a la obtención de un título oficial con validez en todo el territorio nacional y que habilita para el ejercicio profesional.

\section{Estudios.}

En la actualidad, en España se puede cursar formación especializada en las CD (ciencias de la documentación) en los tres ciclos que conforman la educación universitaria (diplomatura, licenciatura y doctorado) (cuadros 4 y 5): en 12 centros se puede seguir la diplomatura en ByD, en 11 la licenciatura en documentación y en 13 el doctorado.

A pesar de que en España la enseñanza profesional en $\mathrm{CD}$ posee una larga tradición histórica, hunde sus raíces a mediados del siglo XIX con una clara vinculación universitaria desde sus orígenes, hay que esperar a la década de los ochenta para que se institucionalice de forma estable y definitiva. Por consiguiente, estamos ante una titulación muy joven; en el curso venidero se cumplirán 20 años de la creación de los prime- ros centros universitarios en Barcelona y Granada (si bien, como es conocido, la escuela de ByD de Barcelona heredaba el bagaje de la antigua institución fundada en 1915). Es en la década de los noventa cuando ve la luz la mayoría de los centros vigentes. Aunque ya parece haberse alcanzado el techo, pues hace dos años tuvo que cerrar sus puertas el primer centro ( $\mathrm{San} \mathrm{Pa-}$ blo-CEU). Es bastante posible que esta tendencia se acentúe en los próximos años.

De las 17 universidades donde se alojan nuestros estudios sólo siete cuentan con centros (facultades) exclusivamente dedicados a su impartición (Alcalá, Barcelona, Carlos III, Complutense, Extremadura, Granada y Murcia). Asimismo, en sólo seis existen departamentos propios (Barcelona, Carlos III, Complutense, Granada, Murcia y Vic), debido a que en la mayoría no se alcanza el número mínimo de profesores permanentes para erigirse en departamento autónomo (12 según la fenecida Ley de Reforma Universitaria, cifra que puede verse elevada por los estatutos que rigen en cada universidad). La denominación dominante de los centros y, sobre todo de los departamentos, es la de $\mathrm{ByD}$, coincidente con el término empleado para designar a nuestro área de conocimiento dentro del catálogo básico de ramas en que se subdivide el conocimiento dentro de la universidad española.

Los centros y los departamentos en los que han encontrado acogida los estudios de documentación que no han logrado o, en algunos casos, no han querido independizarse son de toda índole: desde los de humanidades hasta los científico-técnicos pasando por los de

\begin{tabular}{|c|c|c|c|c|c|}
\hline \multirow{2}{*}{ Curso académico } & \multicolumn{3}{|c|}{ Alumnos matriculados } & \multicolumn{2}{|c|}{$\begin{array}{c}\text { Alumnos que finalizaron } \\
\text { estudios }\end{array}$} \\
\hline & Diplomatura & Licenciatura & Doctorado & Diplomatura & Licenciatura \\
\hline $1983 / 1984$ & 208 & & & & \\
\hline $1984 / 1985$ & 458 & & & 14 & \\
\hline $1985 / 1986$ & 639 & & & 85 & \\
\hline $1986 / 1987$ & 1.120 & & & 152 & \\
\hline $1987 / 1988$ & 1.365 & & & 156 & \\
\hline $1988 / 1989$ & 1.709 & & & 281 & \\
\hline $1989 / 1990$ & 2.253 & & & 454 & \\
\hline $1990 / 1991$ & 2.796 & & & 435 & \\
\hline $1991 / 1992$ & 3.492 & & & 403 & \\
\hline $1992 / 1993$ & 3.772 & & & 762 & \\
\hline $1993 / 1994$ & 4.276 & & & 796 & \\
\hline $1994 / 1995$ & 4.036 & 295 & & 645 & 25 \\
\hline $1995 / 1996$ & 4.056 & 688 & 38 & 614 & 17 \\
\hline $1996 / 1997$ & 4.392 & 933 & 22 & 676 & 91 \\
\hline $1997 / 1998$ & 4.236 & 1.242 & 62 & 810 & 212 \\
\hline $1998 / 1999$ & 4.767 & 1.656 & 88 & 789 & 252 \\
\hline $1999 / 2000$ & 4.859 & 2.831 & 86 & 778 & 265 \\
\hline $2000 / 2001$ & 4.675 & 3.218 & $*$ & $*$ & $*$ \\
\hline $2001 / 2002$ & 4.777 & 3.732 & $*$ & $*$ & $*$ \\
\hline & & & & 7850 & 837 \\
\hline
\end{tabular}

Tabla 4. Evolución del alumnado matriculado y que finalizó estudios de ciencias de la documentación (1983-2002).

* Sin datos.

Fuentes: Instituto Nacional de Estadística. A nuario estadístico 1991, Estadística de la enseñanza superior en España. Curso 1999-2000, y A vances de la estadística de la enseñanza superior en España. Curso 2001-2002. 


\begin{tabular}{|c|c|c|c|c|c|c|}
\hline \multirow{2}{*}{ Universidades } & \multicolumn{3}{|c|}{ Alumnos matriculados } & \multicolumn{3}{|c|}{ Alumnos que finalizaron estudios } \\
\hline & Diplomatura & Licenciatura & Total & Diplomatura & Licenciatura & Total \\
\hline Total & 4.859 & 2.831 & 7.690 & 789 & 265 & 1054 \\
\hline Alcalá de Henares & & 195 & 195 & & 19 & 19 \\
\hline Autónoma de Barcelona & & 37 & 37 & & *** & \\
\hline Barcelone & 574 & 143 & 717 & $*$ & $* *$ & \\
\hline Canlos III & 519 & 155 & 674 & 112 & 47 & 159 \\
\hline Comolutense de Madrid & 607 & 245 & 852 & 113 & **** & 113 \\
\hline Coruña & 183 & & 183 & 33 & & 33 \\
\hline Extremadura & 271 & 161 & 432 & 63 & 16 & 79 \\
\hline Granada & 712 & 459 & 1.171 & 104 & 115 & 219 \\
\hline León & 310 & & 310 & 79 & & 79 \\
\hline Murcia & 420 & 196 & 616 & 68 & *** & 68 \\
\hline Politécnica de valencia & & 184 & 184 & & 10 & 10 \\
\hline Salamarnca & 474 & 177 & 651 & 78 & 58 & 136 \\
\hline Valencia (Estudi General) & 350 & & 350 & 36 & & 36 \\
\hline Oberta de catalunva & & 809 & 809 & & **8 & \\
\hline San Pablo-CEU & 61 & & 61 & 11 & & 11 \\
\hline Vic & 38 & & 38 & $* *$ & & \\
\hline Zaragoza & 340 & & 340 & 92 & & 92 \\
\hline
\end{tabular}

Tabla 5. Alumnado matriculado en el curso 1999-2000 y que finalizó estudios en el año 1999, por universidad.

*Sin datos. $\quad * *$ Sin finalizar primera promoción.

Fuente: Instituto Nacional de Estadística. Estadística de la enseñanza superior en España. Curso 1999-2000.

ciencias sociales. No obstante, son las facultades de humanidades las dominantes, lo cual no es más que una manifestación del tradicional perfil humanístico que originariamente ha tenido nuestra carrera, y del que se va despojando poco a poco.

Por último, comentar que el mapa de titulaciones es bastante coherente con la situación de la infraestructura bibliotecaria y documental del país. Madrid y Cataluña son las zonas con más titulaciones. La principal anomalía es la inexistencia de centros formativos en el País Vasco.

Respecto al doctorado (cuadro 5), señalar lo reciente de su implantación (la mayoría de los programas no tienen más de un lustro de antigüedad) y el hecho de que algunos sean producto de la colaboración entre universidades o entre distintos departamentos. En líneas generales, se caracterizan por su falta de homogeneidad interna y especialización definida, a pesar de lo que pudiera pensarse al hojear sus títulos. Los cursos que los forman y las líneas de investigación que se desarrollan en su interior tienen poca relación entre sí; no responden más que a los intereses científicos concretos de los profesores que los imparten, surgidos, además, muy recientemente. La media de plazas ofrecidas por programa ronda las 25 . La oferta global de plazas oscila entre 250 y 300.

\section{Estudiantes: matriculación y graduación.}

El número de alumnos matriculados en el curso 2001-2002 en enseñanzas universitarias de CD asciende a 8.700 (tabla 4), de los que el 55\% (4.777) está cursando la diplomatura, el $43 \%$ la licenciatura (3.732) y el $2 \%$ el doctorado. Desde la creación de los estudios en 1983, su número no ha cesado de crecer a un pro- medio anual del $22 \%$ en la diplomatura y el $48 \%$ en la licenciatura. No obstante, los ritmos de crecimiento se han desacelerado en los últimos años. Así, mientras que en la década de los ochenta el incremento de alumnos de diplomatura era del $40 \%$ anual, en el último cuatrienio el crecimiento es igual a cero. En la licenciatura la tasa de crecimiento se ha reducido a la mitad. El estancamiento es mayor en la diplomatura que en la licenciatura ya que en el curso 1999-2000, por primera vez, el número de inscritos en primer curso fue superior en la licenciatura (1.575 estudiantes) que en la diplomatura (1.478).

\section{«A partir de 1998 se observa una caída en el número de di- plomados, algo que no ocurre con el de licenciados cuya ten- dencia es ascendente»}

Respecto a los alumnos graduados, indicar que el número de diplomados entre 1983 y 2000 alcanza la cifra de 7.850 y el de licenciados 837 (tabla 4). En los últimos tiempos vienen graduándose anualmente unos mil estudiantes, de los que el $75 \%$ son diplomados y el $25 \%$ licenciados. A partir de 1998, se observa una caída en el número de diplomados, algo que no ocurre con el de licenciados cuya tendencia es ascendente.

En la tabla 5 podemos observar la distribución de alumnos matriculados y graduados por universidades. Es la Universidad de Granada la que cuenta con más estudiantes, seguida por la Complutense y la de Barcelona. En la licenciatura esta clasificación ha cambiado tras la irrupción de la UOC (Universitat Oberta de Ca- 
talunya), que es la primera universidad virtual que ofrece nuestra titulación. El número de estudiantes que ha captado en tan poco tiempo es impresionante. En general, por alumnado, habría que catalogar nuestros estudios como de pequeño tamaño; esto explica que en muchas universidades se haya optado por agrupar nuestros estudios con otros en un mismo centro.

En cuanto a alumnos graduados, también es en Granada

\begin{tabular}{|l|c|}
\hline \multicolumn{1}{|c|}{ Categoría académica } & Número profesores \\
\hline Total & 296 \\
\hline Catedráticos de universidad & 13 \\
\hline Titulares de universidad & 72 \\
\hline Catedráticos de escuelas universitarias & 9 \\
\hline Iitulares de escuelas universitarias & 39 \\
\hline Profesores asociados & 118 \\
\hline Profesores eméritos & \\
\hline Profesores visitantes & 21 \\
\hline Profesores ayudantes & 24 \\
\hline Otros profesores y no consta &
\end{tabular}

Tabla 6. Profesores universitarios del área de biblioteconomía y documentación por categoría académica en el curso 1999-2000.

Fuente: Instituto $\mathrm{N}$ acional de Estadística. Estadística de la enseñanza superior en España. Curso 1999-2000. donde más se diploman y licencian, aunque seguramente habrá quedado relegada a un segundo puesto en estos dos últimos años por la UOC. Por último señalar, como rasgo general, que estamos ante una carrera de clara vocación femenina, pues el $70 \%$ de los estudiantes son mujeres. Este fenómeno ocurre por igual en los tres ciclos.

\section{Profesorado.}

En el curso académico 1999-2000 el número de profesores universitarios del área de ByD se cifraba en 296, de los cuales más de la mitad eran profesores no permanentes (asociados o ayudantes) (tabla 6). Dentro del profesorado permanente (funcionarios de carrera) es la categoría de profesores titulares de universidad la dominante (24\%), muy por encima de las categorías vinculadas a las escuelas universitarias. Esto se debe a la introducción de los estudios de licenciatura y la subsecuente conversión de las escuelas en facultades, lo que conllevó el cambio o la entrada directa, a partir de ese momento, del profesorado que contara con el título de doctor, en la susodicha categoría profesional.

Se trata de un profesorado bastante joven, algo lógico dada la juventud del área de conocimiento, y preferentemente femenino (55\%), aunque en menor porcentaje de lo observado entre el estudiantado y la profesión. Hoy día la mayoría de los docentes ha recibido formación específica en documentación, bien a nivel de primer o segundo ciclo, aunque este fenómeno ocurre más entre el profesorado no permanente. El profesorado permanente mayoritariamente se formó en carreras humanísticas (básicamente filología e historia) o de ciencias sociales (periodismo, sobre todo) y tras un acelerado reciclaje aterrizó en el campo documental. Desde el punto de vista de la titulación, predomina el profesorado no doctor (el porcentaje debe rondar el $60 \%)$.

La recientemente aprobada $L O U$ (Ley Orgánica de Universidades) ha introducido cambios importantes en la selección, acceso y promoción del profesorado universitario que, a no mucho tardar, provocará cambios importantes en su estructura y composición.

\section{Los canales de comunicación científica y profesional}

Se dedica este apartado a describir cuáles son los medios de comunicación creados por la comunidad documental española para trasladar, tanto interna como externamente, la información que se produce en el propio campo.

\section{Editoriales especializadas.}

$\mathrm{Su}$ presencia es un signo de institucionalización social de la profesión o disciplina. Pone de manifiesto, de una parte, la existencia de capacidad productora de literatura profesional, y de una necesidad y demanda social de otra. Pues bien, hoy día contamos con una editorial especializada en el campo que es Ediciones Trea. Radicada en Gijón, posee una colección denominada Biblioteconomía y administración cultural dedicada a publicar obras de carácter técnico, estudios y ensayos sobre biblioteconomía, archivística, documentación, museología, bibliografía, gestión cultural y otras materias afines. En estos dos últimos años ha sacado a la luz 55 obras. Cabría citar, asimismo, la Biblioteca del libro de la Fundación Germán Sánchez Ruipérez, que tan importante papel jugó en los ochenta y primeros noventa, aunque hoy día ha bajado considerablemente su nivel productivo. Otros editores que hacen incursiones más que esporádicas en nuestro campo son Síntesis (con una colección de más de 20 manuales del área), Arco Libros y Diego Marín Librero. Las asociaciones profesionales, y especialmente Anabad, otrora las monopolizadoras de la producción bibliográfica profesional, han bajado en su capacidad de realización editorial. 


\begin{tabular}{|c|c|c|c|c|}
\hline Tilinalno & Purickefisitled & $\begin{array}{l}\text { Uitumo fasciculo } \\
\text { publicada }\end{array}$ & 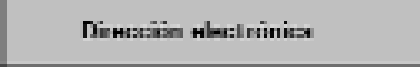 & Fillive \\
\hline 보 & anual & n. $6 \mathrm{de} 200 \mathrm{Z}$ & netp: $/ /$ www 1.madrld.arg/topem $/$ & Scruklo Reqlonal del Lero y Bblotecas de Madrid \\
\hline Riblanl wex mel hox & Nemped $t \times 1$ & $n>2+2002$ & 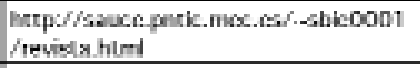 & $\begin{array}{l}\text { Seminarb pemsencente de billbercas escalans } \\
\text { de Tuentabrats }\end{array}$ \\
\hline Uoletin acal & tnmestral & n. $1 / 2$ de 2002 & 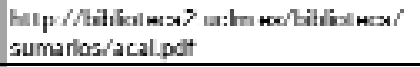 & hoocacion de Mrehweros de Castilla y Leon \\
\hline 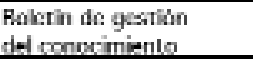 & mernearal & Oe:tubre ide 2002 & 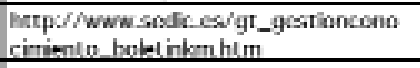 & 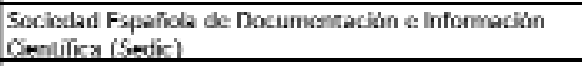 \\
\hline 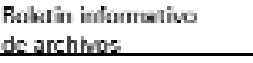 & meneual & ก. 11 de 2002 & 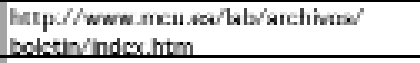 & Subdreceion Gencral de Archwos Letatales \\
\hline 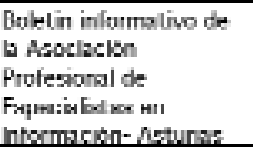 & mencual & Julio de 2002 & nttp: $/ /$ www.apclorg/bolctin.htm & 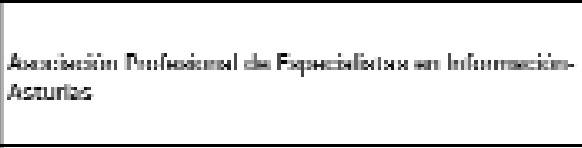 \\
\hline 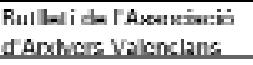 & trimestral & n. 3 de 2002 & 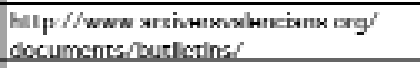 & Aseoclacib d'Antucrs Valenclenz \\
\hline 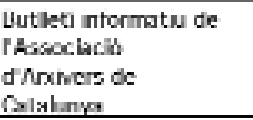 & bumestral & n. 6 de 2000 & 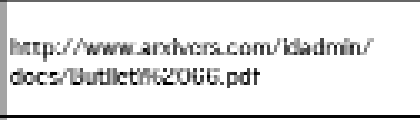 & hesociacio d'Anovers de Catalunya \\
\hline Crfr balmalin de bs Setic & Irimesentexl & n. 2 de 2002 & $\begin{array}{l}\text { hetp: } / / \text { www.sedic.es/p_boletin } \\
\text { efrehim }\end{array}$ & Snetir: \\
\hline 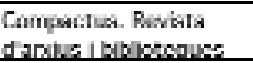 & cuatnmestral & n. 2 ds 2002 & 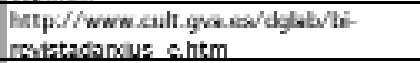 & 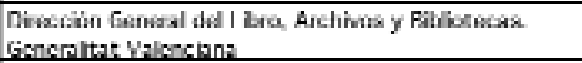 \\
\hline Conco belilotccario & moneual & $\begin{array}{l}\text { Senplinentas Ilm } \\
\text { avoez }\end{array}$ & 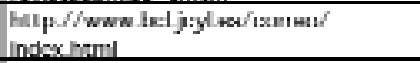 & 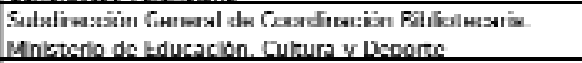 \\
\hline $\begin{array}{l}\text { Document: full } \\
\text { informatia bal Cakah: }\end{array}$ & Limbatial & n. 5 de 7008 & $\begin{array}{l}\text { hutp:/www.cobdc.org/06oubb' } \\
\text { bas:un?.ht ml }\end{array}$ & 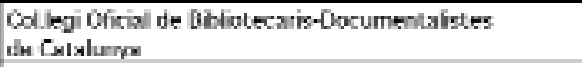 \\
\hline 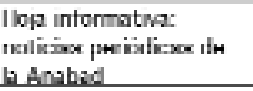 & bimestral & n. 1 de 2002 & 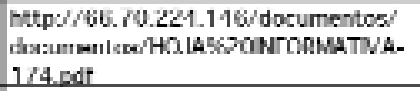 & 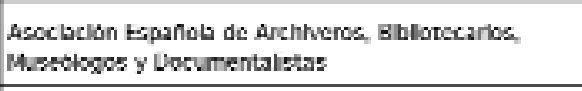 \\
\hline Ifa tilkaxl & wearsenal & n. $3 \mathrm{~d}=7007$ & $\begin{array}{l}\text { http://www.cobdc.org/UIgrups/' } \\
\text { infoblecat/hinfoblecat.hem }\end{array}$ & Cablin: y Avwi \\
\hline Newo & meneusl & n. 2 de 2000 & |nttp: $/ /$ www.doc6.es/docti/newo.html & Dout \\
\hline
\end{tabular}

Cuadro 6. Boletines informativos publicados en España sobre archivística, biblioteconomía y documentación.

\section{Boletines informativos.}

Me ocuparé en este apartado de identificar y analizar las publicaciones periódicas que, en nuestra especialidad, tienen una finalidad eminentemente informativa como son los boletines que ofrecen noticias sobre la actualidad profesional (actividades organizadas por la administración bibliotecaria o de los archivos, bibliotecas y centros de documentación, nombramientos, legislación, etc.), anuncian reuniones y eventos científicos y profesionales, informan sobre personas, sobre productos comerciales, reseñan novedades editoriales, dan a conocer progresos científicos, técnicos, educativos o económicos. Y todo ello lo hacen principalmente en forma de artículos o notas breves, con información general, no detallada, utilizando una redacción clara y ágil. La existencia de publicaciones de este tipo es otro claro signo de institucionalización social de una profesión. Significa que el sector documental es activo y dinámico, capaz de generar las más variadas actividades que responden a los intereses de un cuerpo social sólidamente establecido y que deben ser trasmitidas a la comunidad.

En la actualidad contamos con unos 15 boletines informativos realmente vivos (cuadro 6). Conviene advertir que, aunque son todos los que están, es posible que no estén todos los que son. Las características de estas publicaciones es la siguiente:
- Son productos jóvenes: el $60 \%$ ha nacido en el último lustro; por el contrario, la más antigua data de 1980.

-De periodicidad corta: el 35\% es mensual y el $60 \%$ se publica con una periodicidad inferior a los dos meses. Es lógico que así sea atendiendo a la propia naturaleza de estas publicaciones.

-Aunque algunas no lo hagan estrictamente, la mayoría viene cumpliendo la periodicidad anunciada, lo cual es signo de profesionalidad.

- Se encuentran auspiciadas por las asociaciones profesionales (60\% de las publicaciones) o por algunos órganos de la administración bibliotecaria estatal y autonómica (30\%).

- Casi la práctica totalidad poseen versión electrónica accesible gratuitamente a través de la Red.

-Desde el punto de vista temático, predominan las publicaciones especializadas frente a las generales. Por ramas profesionales son las publicaciones dirigidas al colectivo bibliotecario las que más abundan (40\%), seguidas por las de contenido archivístico $(33 \%)$.

\section{Revistas científicas.}

En la actualidad, en España vienen publicándose regularmente 27 revistas científicas sobre archivística, 


\begin{tabular}{|c|c|c|c|c|c|}
\hline Thüns & Ano funtecicin & Purianfiritad & n numen putiks & Dirka:iin mbel ninivex & Fefin \\
\hline 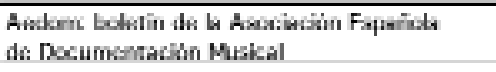 & 1991 & semestral & n. 1 de 2001 & 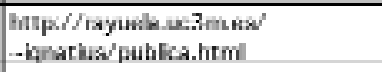 & 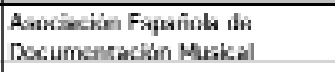 \\
\hline $\begin{array}{l}\text { Aldeczisana } \\
\text { Analcs de documcntacion }\end{array}$ & $\begin{array}{l}\text { 19y: } \\
\text { 19ys }\end{array}$ & $\begin{array}{l}\text { scmestral } \\
\text { anual }\end{array}$ & $\begin{array}{l}1990 \\
2002 \\
\end{array}$ & 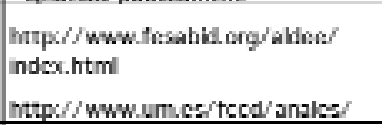 & 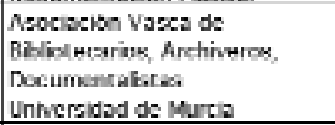 \\
\hline 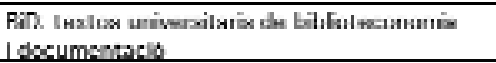 & 1998 & semcstral & n. 1 de 2002 & inttp://www.ub.ce/biblo/bid/ & Untwersidod de Uareclong \\
\hline Bidurma & 1987 & anual & 2001 & & Ayuntamiento de Renteria \\
\hline 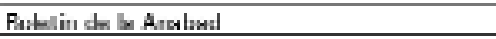 & 19.50 & Irimusel|al & n. 3 . $\ln 7001$ & & Arsaliand \\
\hline 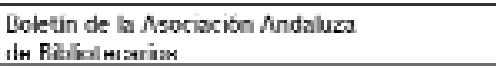 & 1984 & Irimased IxI & m. 3 dim 2007 & hllp. $/ /$ www selt wer & 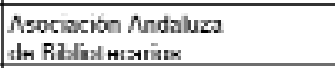 \\
\hline Loletin de la Nabodom & 1990 & trmestral & n. $1-2$ de 2002 & & 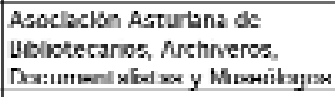 \\
\hline 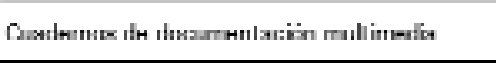 & 1998 & stural & an 1 dim 2000 & 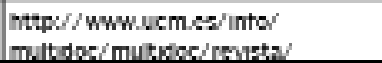 & 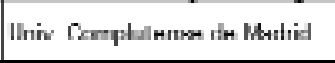 \\
\hline Cybemetrics & $199 /$ & anual & 2001 & 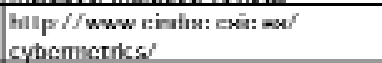 & Clnsbc \\
\hline $\begin{array}{l}\text { Documentaclion de las clenclas de } \\
\text { ta intormacion }\end{array}$ & $19 / 6$ & anual & 2002 & 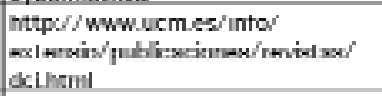 & Unw. Complutense de Madnd \\
\hline Futucursin y hablinl wes & 1989 & trimed $1 \times 1$ & in 5 tim 2000 & & $\begin{array}{l}\text { Neociseion Cuitural Loucacibn } \\
\text { y Rihlini med }\end{array}$ \\
\hline El protealonal de la lntomocion & 1992 & bimcstral & n s de 2002 & 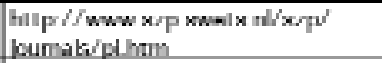 & Swet \& $\angle$ citlinger \\
\hline Item & 1946 & semestral & n. 2 de 2002 & $\begin{array}{l}\text { Imrtp://www.cobdcorg/o6publ } \\
\text { itempeces.html }\end{array}$ & 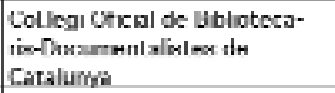 \\
\hline $\begin{array}{l}\text { bumal of Spantah research on information } \\
\text { revence }\end{array}$ & 2000 & scmestral & $\ln 2$ de 2000 & 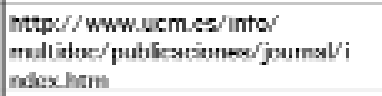 & Unn. Complutense de Madnd \\
\hline Ligall & 1905 & semestral & n. 2 de 2001 & $\begin{array}{l}\text { hrtp://www.arxhers.com/cat/ } \\
\text { haplase }\end{array}$ & $\begin{array}{l}\text { Associacls d'Andvers de } \\
\text { Gingluma }\end{array}$ \\
\hline Merodoc de intamacion & 1994 & bimcstral & jul 02 & 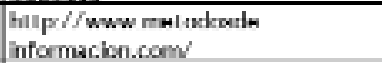 & 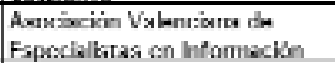 \\
\hline 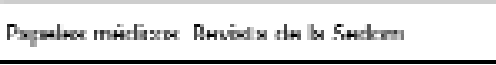 & $190>$ & Irimmed ral & $\ln 3 \mathrm{tim} 2000$ & $\begin{array}{l}\text { http://www.ncwesdicioncs. } \\
\text { com/nenul him }\end{array}$ & 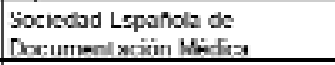 \\
\hline Ploogace do bibirofilia & 1998 & mimatseral & $\ln 3$ de 7007 & & Phorace do RElbolita \\
\hline Keveta espafiola de documentacion cientihes & $19 / 6$ & trmertral & n. 3 de 2002 & $\begin{array}{l}\text { inrtp://www.chinloc.csic.es/ } \\
\mathrm{redc} / \mathrm{redc} \cdot \mathrm{htm}\end{array}$ & $\begin{array}{l}\text { Centro de Intormocion y } \\
\text { Documenl sciain Cient ifics } \\
\text { (C.indoc:) }\end{array}$ \\
\hline $\begin{array}{l}\text { Rouvese genoural do informuciàn } \\
\text { y documentacion }\end{array}$ & 1992 & semestral & n. 1 de 2002 & $\begin{array}{l}\text { Inttp://www.ucm.ce//into/ } \\
\text { exlersib/publicwciones/revisiss// } \\
\text { nilianl }\end{array}$ & Unw. Complutenes de Modnd \\
\hline Stive & 1995 & semesirsl & & $\begin{array}{l}\text { inttp://tylunzares/scikl/ } \\
\text { schilnt }\end{array}$ & Univ. if Zxrogucx \\
\hline 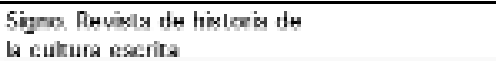 & 1994 & anual & 2007 & & $\begin{array}{l}\text { Unionersidxd de Alesti } \\
\text { de: Henentes }\end{array}$ \\
\hline $\begin{array}{l}\text { I abula: revieta de archivos de Castila } \\
\text { y losin }\end{array}$ & 1993 & sanual & 2002 & 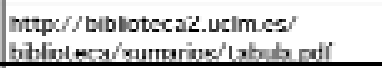 & $\begin{array}{l}\text { Neociseion de Arehneree de } \\
\text { Castils y l win }\end{array}$ \\
\hline Tejucla & 7000 & Anual & 7001 & $\begin{array}{l}\text { hinp.//66.70 } 374.146 / \\
\text { documentos/documentos/tejuclo. } \\
\text { odl }\end{array}$ & Ansabad Murcia \\
\hline TK Acociackn Nawarra de Plblotecarboi & 1996 & scmestral & n. 2 de 2001 & & 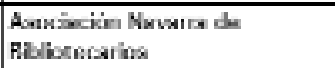 \\
\hline 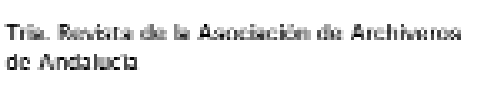 & 1993 & anual & 1999 & 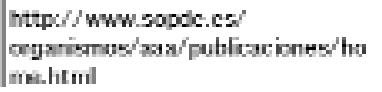 & 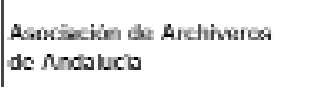 \\
\hline
\end{tabular}

Cuadro 7. Revistas científicas publicadas en España sobre archivística, biblioteconomía y documentación.

* Fecha de la consulta: enero 2003.

biblioteconomía, documentación y campos afines (cuadro 7). Su retrato robot es el que sigue:

- Revista joven con menos de diez años de vida: 15 de los 27 títulos circulantes han nacido en la última década; por el contrario sólo 3 superan los 25 años de vida; 1998 aparece como el año en que más publicaciones han visto la luz. Por el contrario, en estos dos últimos años no ha aparecido ninguna, lo cual puede significar que se ha alcanzado el punto óptimo de saturación.

- Son de periodicidad amplia: predominan abrumadoramente las anuales o semestrales (18). Como no- vedad, en el último año, las dos únicas revistas mensuales existentes (Educación y biblioteca y El profesional de la información) han ampliado su periodicidad.

- Se encuentra patrocinada por una asociación profesional (catorce) o un centro universitario donde se imparten los estudios de ByD (ocho).

- Se publica fundamentalmente en Madrid (diez) o en Barcelona (cuatro).

-Posee una cobertura, alcance y público general. A pesar de que en los últimos años han empezado a surgir revistas especializadas en los distintos ámbitos 


\begin{tabular}{|c|c|c|c|}
\hline Denominacikn & Direcciōn clectrúnica & Orpanizaciôn patrocinadora & $\mathrm{N}^{*}$ suscriptores" \\
\hline 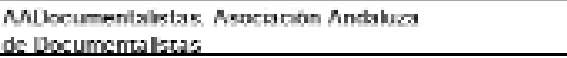 & 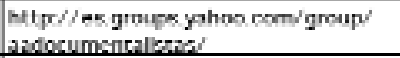 & Acocbision Andaluza de Documentaktas & \\
\hline Nethmala & 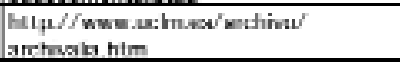 & 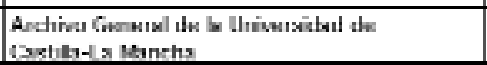 & \\
\hline 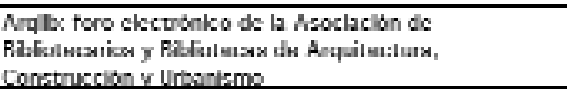 & 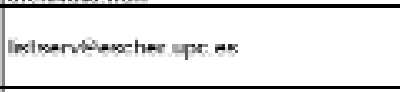 & 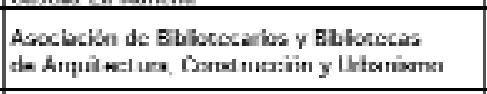 & \\
\hline Mrutorume toeo sobre archnistics & 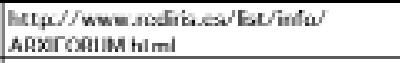 & Nssocnono d Anovers de Latalumga & $1.3 / 3$ \\
\hline 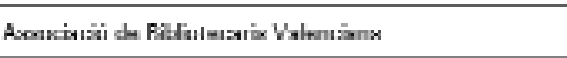 & 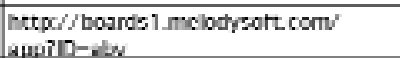 & 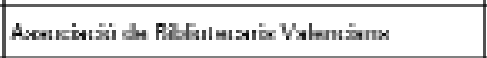 & \\
\hline 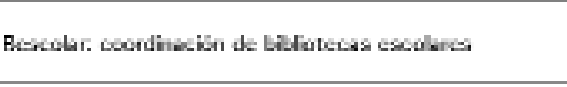 & $\begin{array}{l}\text { nttpo//www.redins.es/lst/into/ } \\
\text { bescolar.hem }\end{array}$ & 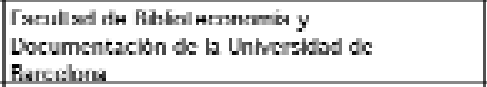 & 271 \\
\hline 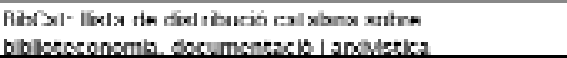 & blocatelictuctes & Cobdc y Avel & \\
\hline 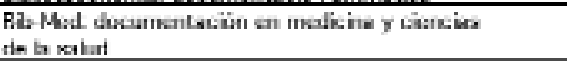 & 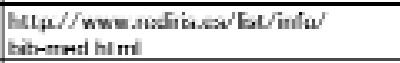 & 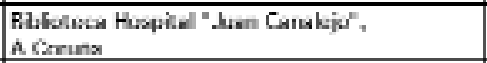 & 149 \\
\hline 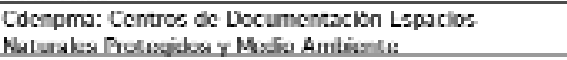 & & & 68 \\
\hline $\begin{array}{l}\text { Chedoc: documentacibn y nucvas tecnologita en } \\
\text { al tüe experial }\end{array}$ & 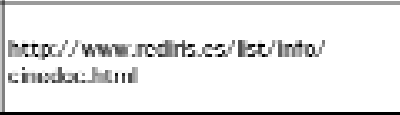 & 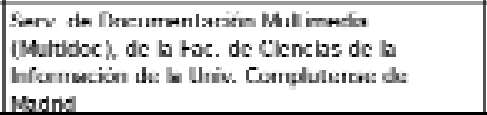 & 54 \\
\hline 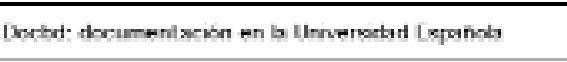 & $\begin{array}{l}\text { lactpo//wwe.redirta.es/'Ev/info' } \\
\text { dontat himl }\end{array}$ & Unwersatad de Zarmgora & 21 \\
\hline Desusfole & $\begin{array}{l}\text { nttpo//www.umes/to-documentacion/' } \\
\text { docuEsh/ }\end{array}$ & 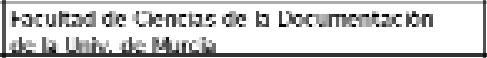 & \\
\hline \multirow{2}{*}{$\begin{array}{l}\text { Demi-Ls: foro espahol del Dubin Core Metadata } \\
\text { Eitiative }\end{array}$} & \multirow{2}{*}{ 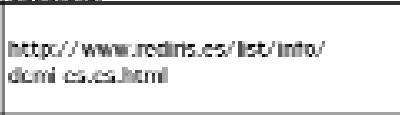 } & 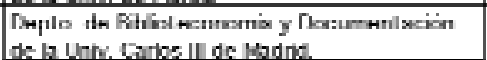 & \multirow[b]{2}{*}{753} \\
\hline & & 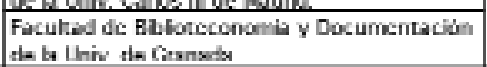 & \\
\hline Fencibat & 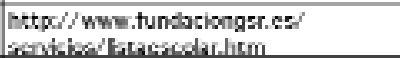 & 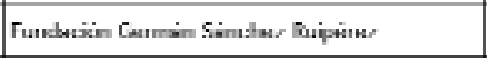 & \\
\hline 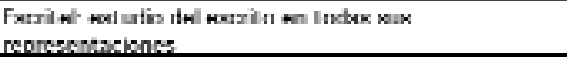 & 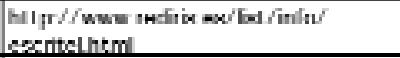 & Acocbelon tepanola de belologla & rs \\
\hline I clet fuentes de intormacion y documentacion en anex & httpr//enthrs usal ex/merio/ hisel & $\begin{array}{l}\text { Fuc. de Traduccièn y Documentación, Lnik. } \\
\text { de Ssbmansa }\end{array}$ & 1206 \\
\hline linupo de I rabajo de LN & Attp//www.anabsd.org/scthidades/ & Nonabod & \\
\hline 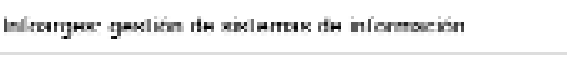 & 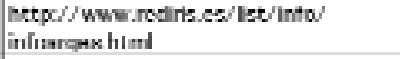 & & \\
\hline 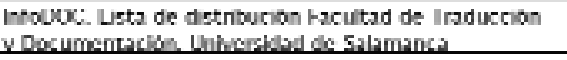 & 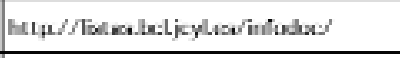 & 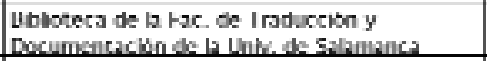 & \\
\hline Intemet y bblotoses & 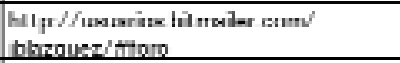 & & \\
\hline $\begin{array}{l}\text { Eho ES: conocimicrto en sletemas de infomachon } \\
\text { y dhusamenlan:iin }\end{array}$ & 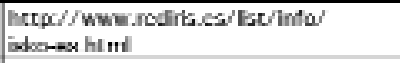 & bekn Tequars & $2 x 1$ \\
\hline 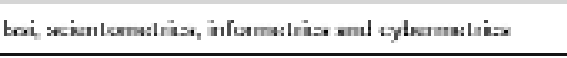 & 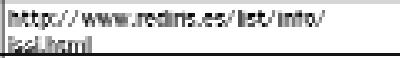 & $\begin{array}{l}\text { Centro de intormacion y Uocumentacion } \\
\text { Chentifiendach) }\end{array}$ & 154 \\
\hline 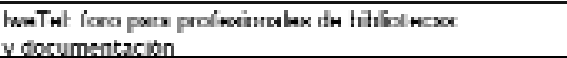 & 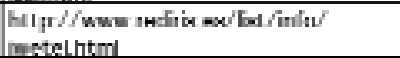 & U protesional de la intormacion (LHI) & 1.612 \\
\hline 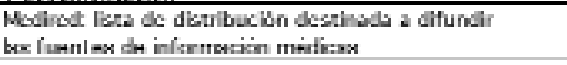 & 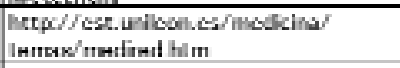 & IInivereatsed if Ifent & 287 \\
\hline 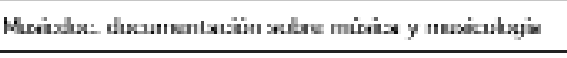 & 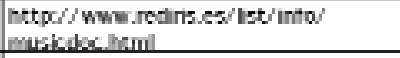 & & 190 \\
\hline 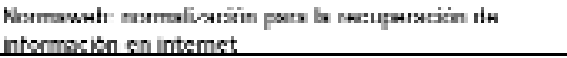 & hetp///letas.bcl|kyles/normawcb/ & Scdk y Cindoc & \\
\hline 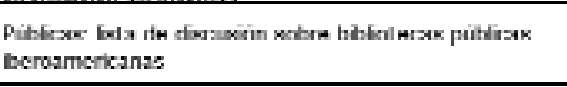 & |nctp//letaz.bcl|kyles/publicas/ & 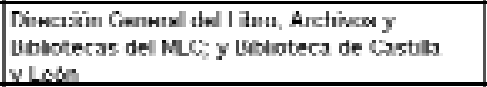 & \\
\hline 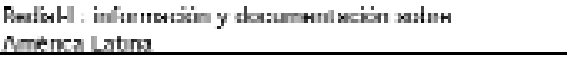 & 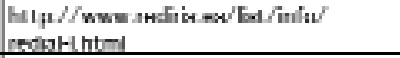 & Cindoc & $z M$ \\
\hline 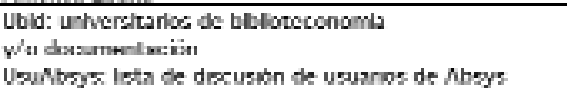 & 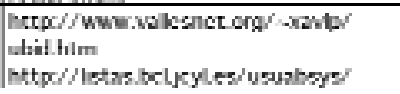 & & \\
\hline
\end{tabular}

Cuadro 8. Listas de distribución existentes en España sobre ciencias de la documentación.

* Se ofrecen datos sólo de las listas gestionadas por Redlris

de las ciencias documentales (archivística, documentación musical, multimedia, biblioteconomía escolar), lo cual sería un síntoma de madurez, predominan todavía las publicaciones que se dirigen a todos los profesionales que trabajan en los sectores de actividad comprendidos por las profesiones documentales. Esto no es óbice para que sea el colectivo bibliotecario el que concite más atención por parte de las revistas.

- Tiene una estructura editorial suficientemente consolidada y diversificada pero no profesionalizada, de tamaño mediano, de procedencia local y filiación preferentemente académica. Son mayoría las revistas en las que existe, de forma diferenciada, un equipo responsable de los contenidos científicos (selección, evaluación, decisión acerca de los originales a publicar, fijación de la política editorial) y un equipo técnico encargado de la edición y publicación (diseño, composición y montaje), impresión, distribución, ventas y suscripciones, publicidad y gestión económico-administrativa.

\section{Foros electrónicos.}

También conocidos por el nombre de listas de distribución, de correo o de discusión, son una nueva e in- 


\begin{tabular}{|c|c|c|}
\hline sutor & ntow & boincriat \\
\hline & 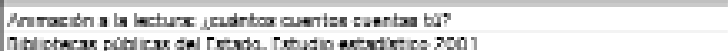 & 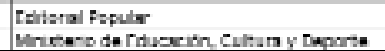 \\
\hline & 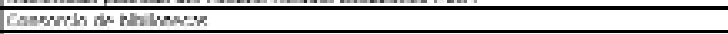 & 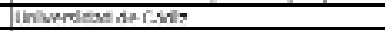 \\
\hline & 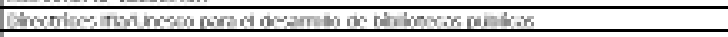 & 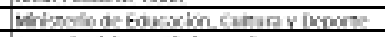 \\
\hline & 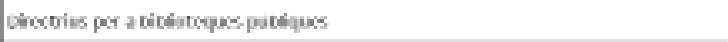 & 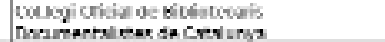 \\
\hline & 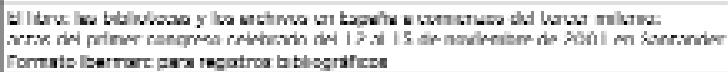 & 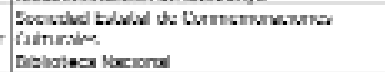 \\
\hline & 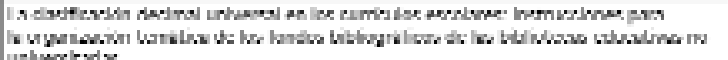 & 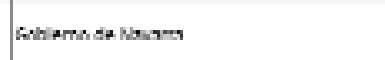 \\
\hline & 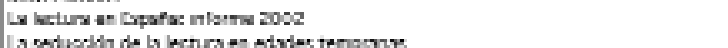 & 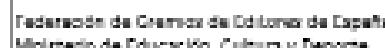 \\
\hline & 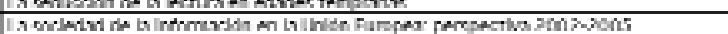 & 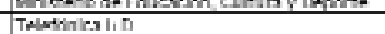 \\
\hline & 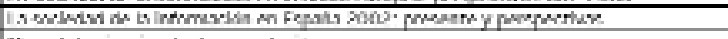 & 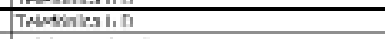 \\
\hline & 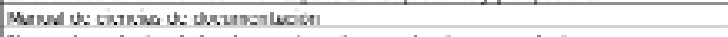 & Euksons: Finenck: \\
\hline & 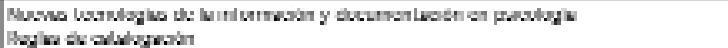 & 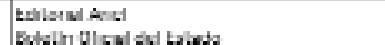 \\
\hline & 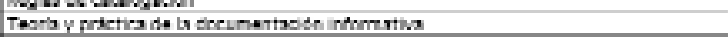 & Patseral heal \\
\hline & 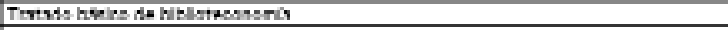 & 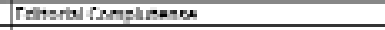 \\
\hline 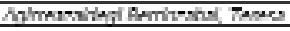 & 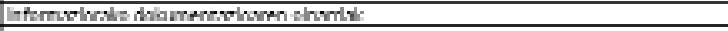 & 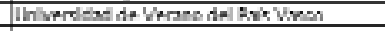 \\
\hline 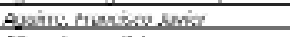 & 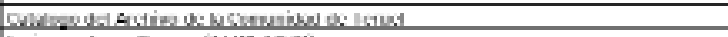 & 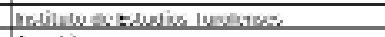 \\
\hline Alece lutron latuse & 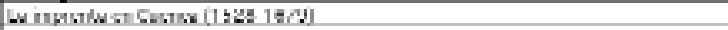 & Asw biss, \\
\hline 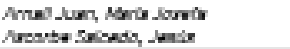 & 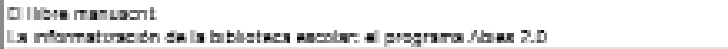 & 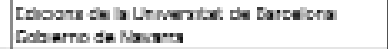 \\
\hline 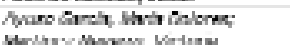 & 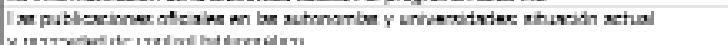 & Doge Mela Ltase batur \\
\hline 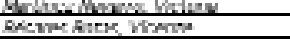 & 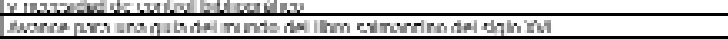 & 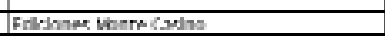 \\
\hline 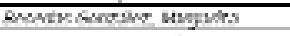 & 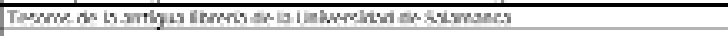 & 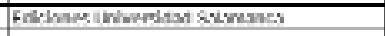 \\
\hline 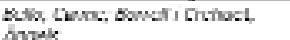 & 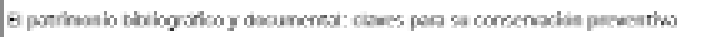 & Ealdhes Tnes \\
\hline 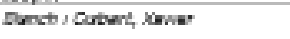 & 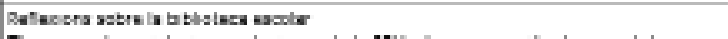 & 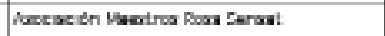 \\
\hline Bubly Movore, bnuque & 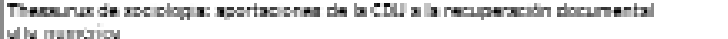 & Eucty Mensta, tenqua \\
\hline 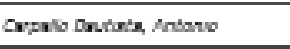 & 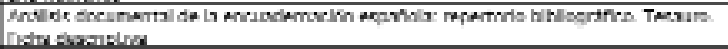 & 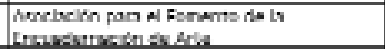 \\
\hline 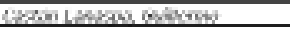 & 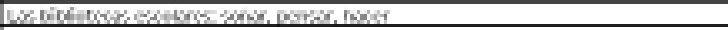 & 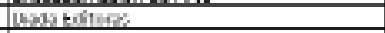 \\
\hline 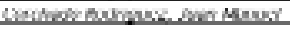 & 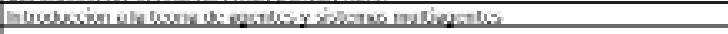 & 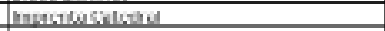 \\
\hline 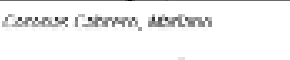 & 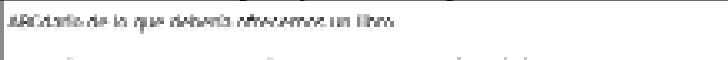 & 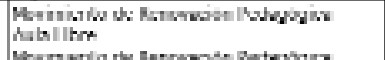 \\
\hline Couns Lidntru, Maven & 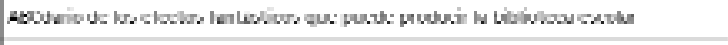 & 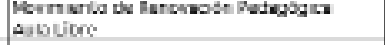 \\
\hline 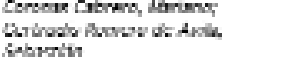 & 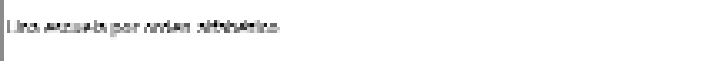 & 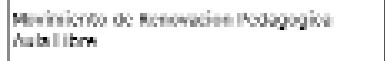 \\
\hline 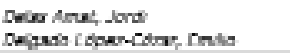 & 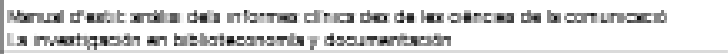 & 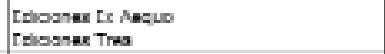 \\
\hline 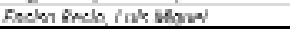 & 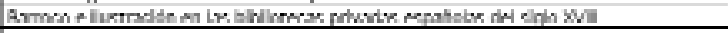 & 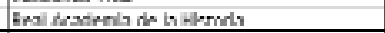 \\
\hline 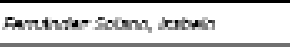 & 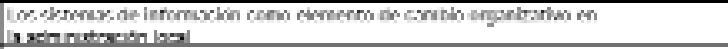 & 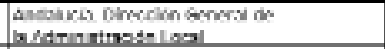 \\
\hline 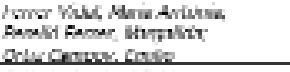 & 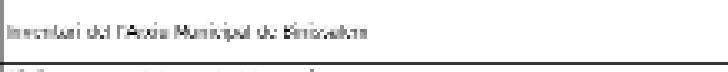 & 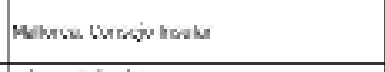 \\
\hline 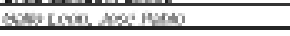 & 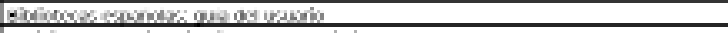 & Aingaboindive \\
\hline 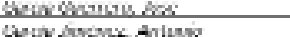 & 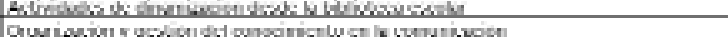 & 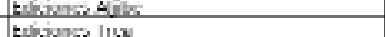 \\
\hline 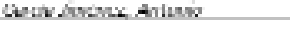 & 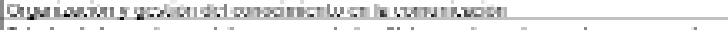 & thavanse lox \\
\hline 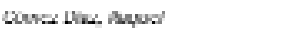 & 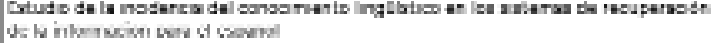 & 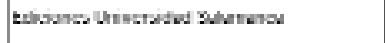 \\
\hline Gsear inerivitar Joeth & 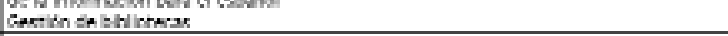 & 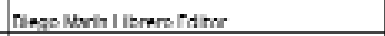 \\
\hline Inemsine anver, fut & Proced metta de vaibrocth dseumenty & 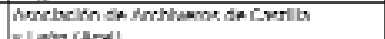 \\
\hline 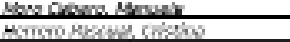 & 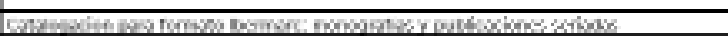 & 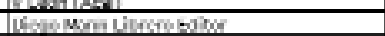 \\
\hline 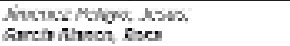 & 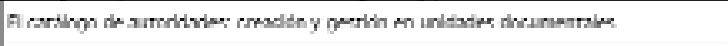 & Frlithnear Tres \\
\hline 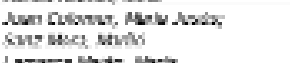 & 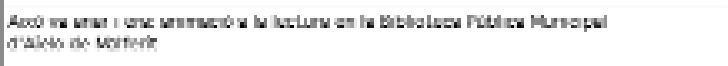 & Apanthericitio Aisto ac Mul. \\
\hline 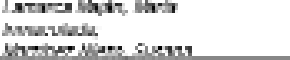 & 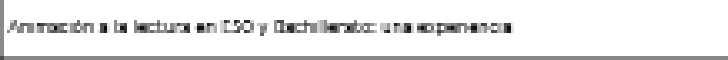 & 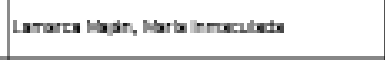 \\
\hline Lencoive, r. Mond & 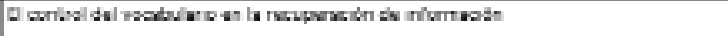 & Unworatad da Wercta \\
\hline 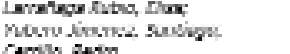 & Utrea, kcistra y nededena & Unvoratad do Could b-La Morcta \\
\hline 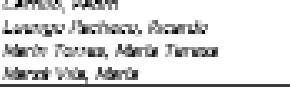 & 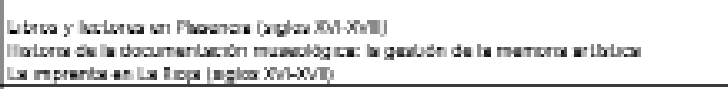 & 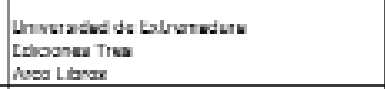 \\
\hline 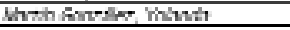 & 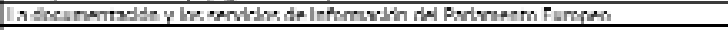 & Frillehoner Tres \\
\hline 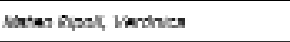 & 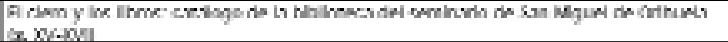 & 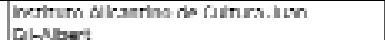 \\
\hline 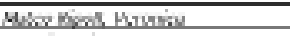 & 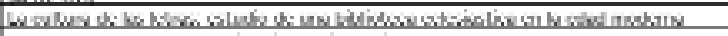 & 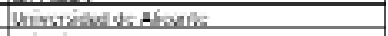 \\
\hline Mansis. & 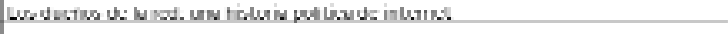 & Eshiarivi Fasuler \\
\hline 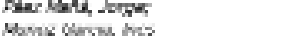 & 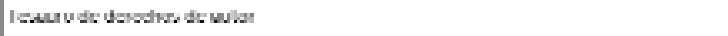 & $\omega$ \\
\hline 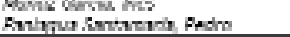 & 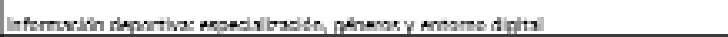 & Ema \\
\hline 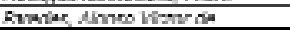 & 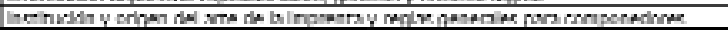 & falloner ratming \\
\hline 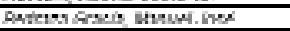 & 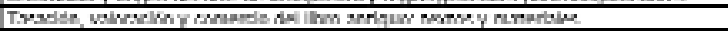 & 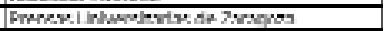 \\
\hline And ane bescis & 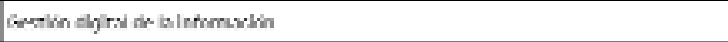 & 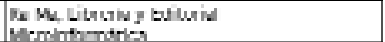 \\
\hline 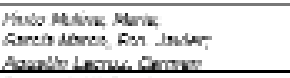 & 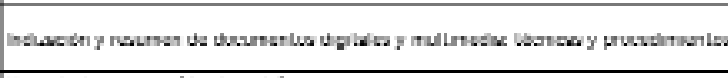 & thloanea Itra \\
\hline Simpina on sing & 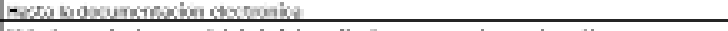 & minsmien \\
\hline 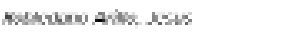 & 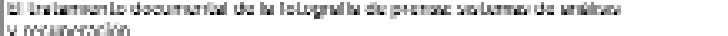 & Activina \\
\hline 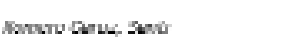 & 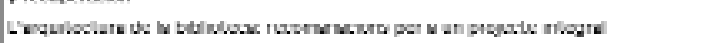 & 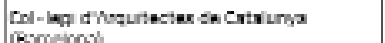 \\
\hline Rov, nev & 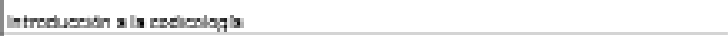 & 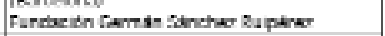 \\
\hline Swhut Raskere Anot: & 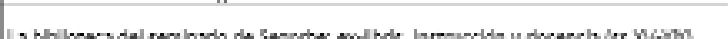 & 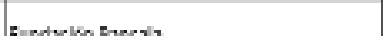 \\
\hline 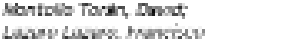 & | STE & 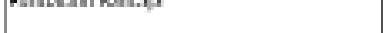 \\
\hline 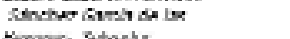 & 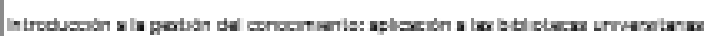 & 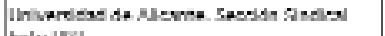 \\
\hline 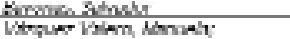 & & \\
\hline Mavo Punk Giens & 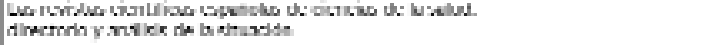 & celk \\
\hline 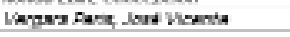 & 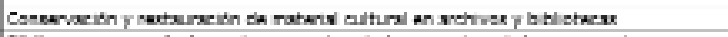 & 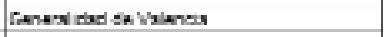 \\
\hline 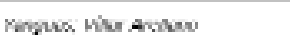 & 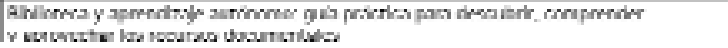 & 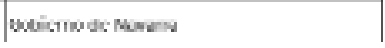 \\
\hline
\end{tabular}


teresante modalidad comunicativa surgida al calor de las nuevas tecnologías que ha traído consigo la implantación de internet. Ante todo, son medios de comunicación, es decir, sirven para transmitir y recibir información; pero están dotados de unas características que les hacen tener una personalidad peculiar y cumplir unas funciones únicas. Yo destacaría, por encima de todo, el hecho de que los productores y consumidores de información en este medio, esto es, los autores y lectores, son los mismos a un tiempo y los responsables directos de la información circulante. Si a esto unimos su rapidez de transmisión y recepción, carácter interactivo (posibilidad de interpelación) y su amplia difusión (alcance simultáneo a todos los suscriptores de la lista), podemos entender su papel como embrión de auténticas comunidades virtuales. En este sentido, su existencia puede interpretarse como un indicador más de institucionalización social de un colectivo profesional.

Son 29 los foros electrónicos identificados en nuestra área (cuadro 8). Éstas son sus características:

- Son jóvenes, aunque es un rasgo general a las listas de distribución en España. Casi el 90\% no llega a los cinco años de vida. No obstante, conviene destacar que contamos con el foro más antiguo en castellano (Iwetel), que también es uno de los de mayor número de suscriptores en todos los ámbitos. Además, de los 12 foros electrónicos gestionados por Rediris que superan los mil suscriptores, tres son de documentación (Iwetel, Arxiforun y Fidel). Esto quiere decir que nuestro campo se sitúa en vanguardia.

-Predominan los auspiciados por asociaciones profesionales $(31 \%)$ o centros universitarios $(24 \%)$, aunque, al contrario de lo que ocurre con los medios de comunicación descritos, los promotores pertenecen a sectores de actividad muy diversos.

- Casi la mitad de las listas están alojadas y mantenidas en servidores de Rediris.

- Los focos de interés es muy variado, en consonancia con lo dicho anteriormente. Además, el grado de especialización es mayor, por lo que resultad difícil categorizarlas temáticamente.

\begin{tabular}{|c|c|}
\hline Bases de datos & Dirección electrónica \\
\hline Lededor & http://www.inforares.es/bedocht/n \\
\hline Roblograsio de archwos & 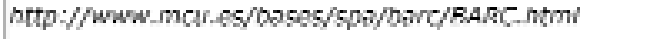 \\
\hline Dalalliske & hue://nnuario.usal.es/dkc.hun \\
\hline Documant & 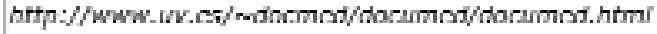 \\
\hline $750 c-6 y 0$ & http://www cindoc csic es/prod/dbsconsenthw \\
\hline Read & http: $/ /$ www.escdoc.er/servoos/redf.htm \\
\hline
\end{tabular}

Cuadro 10. Bases de datos bibliográficas españolas sobre ciencias de la documentación.

\section{La literatura científica y profesional}

Un cuerpo de literatura científica y profesional abundante y diversificado muestra, de un lado, la capacidad de generar conocimiento que tiene una comunidad científica y, de otro, la naturaleza y proporción de sus necesidades de información. Dicha literatura sirve para diferentes fines. El primero de ellos es el informativo en el sentido más periodístico del término (divulgar lo que ocurre en el campo). El segundo, es el formativo (producir textos que sirvan para la enseñan$\mathrm{za}$, adiestramiento y formación de los profesionales en ejercicio); el tercero es dar salida a la investigación generada.

\section{«La existencia de más de una docena de programas de doc- torado con más de $\mathbf{2 0 0}$ alum- nos inscritos es un factor clave para la creación de una masa crítica de investigadores»}

Considerando el número de documentos anualmente indizados por las bases de datos españolas especializadas en $\mathrm{ByD}$ (sobre todo Isoc-ByD), el número de revistas circulantes, el de monografías registradas en el Isbn y el número de congresos y jornadas celebradas, podemos estimar que en 2002 la literatura científica y profesional en ByD en España superó la cifra de los mil documentos publicados. De ellos casi la mitad serían comunicaciones y ponencias a congresos, un tercio artículos en revistas y un $15 \%$ monografías. La mayoría de estas monografías son textos educativos (casi el $40 \%$ corresponden a material docente editado electrónicamente por la $U O C$, que tiene por política registrarlo sistemáticamente). Los títulos de las monografías publicadas en 2002, excluido dicho material educativo se muestra en el cuadro 9.

El indicador más representativo del alto volumen adquirido por la literatura científica y profesional española en CD es la existencia de seis bases de datos bibliográficas que cubren todo el espectro documental (cuadro 10). De ellas dos están más especializadas (archivos y documentación médica). Las bases de datos aparecen como una organización imprescindible en la regulación de los flujos informativos y surgen como consecuencia inmediata del incremento en la producción de conocimiento y el consumo de información. La práctica totalidad de ellas nace en los noventa, que es el período, como vengo apuntando reiteradamente, en que se hace paten- 


\begin{tabular}{|c|c|c|c|}
\hline Autores & Tntula & Revisto & Tipo documento \\
\hline \multicolumn{4}{|c|}{2002} \\
\hline Alsond, L. M & 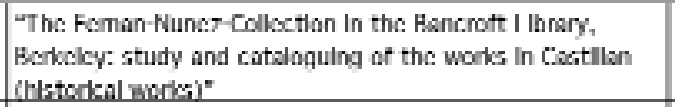 & 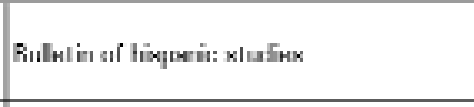 & Rнсинітім \\
\hline Bordons, M; Luivets, M. A. & $\begin{array}{l}\text { "Intcredleciplinarity of Sposnteh cardlovoscular } \\
\text { reseasch teame" }\end{array}$ & Wevsta espanola de cardiologia & Neticulo \\
\hline 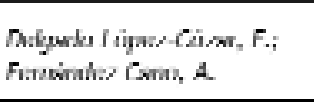 & 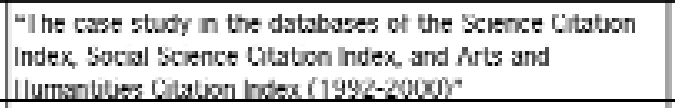 & Arbor. Oencla, penesmilento y culturs & Articula \\
\hline 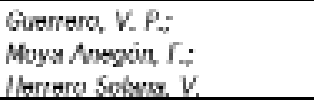 & $\begin{array}{l}\text { "Automatic ertraction of relationshipa between terms } \\
\text { by mosns of Kohoncn's alporthm" }\end{array}$ & Ubrary a intormation seicnce rescarch & Articulo \\
\hline 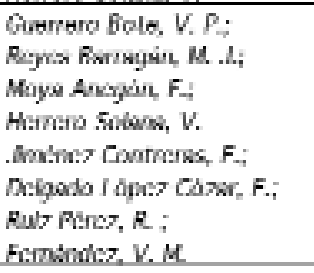 & $\begin{array}{l}\text { "Methods for the analysis of the uses of scientinc } \\
\text { intormation the case of the Univereity of textremodura } \\
(1996-/) \\
\text { "impact tactor rewards aftect Spanish researeh" }\end{array}$ & I ibal & Aurticiala \\
\hline 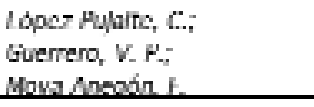 & "A test of gencetic slgoritive in relevance focrlbsck" & Infonmation processing a manogement & Articula \\
\hline Moguel, \& s. & "A new concept of knowledoe" & Online intormation remew & Lditornal \\
\hline 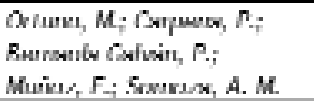 & 'Teyword detectoon in natural langusaes and dns' & Lurophyses letters & Neticulo \\
\hline 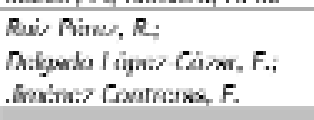 & 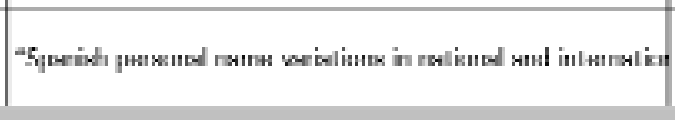 & 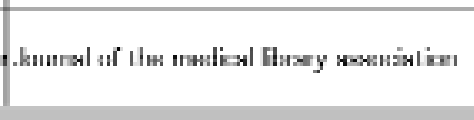 & Áliala \\
\hline \multicolumn{4}{|c|}{2001} \\
\hline $\begin{array}{l}\text { Cabrera, A, Cabrora, t. t.; } \\
\text { Hacise. }\end{array}$ & 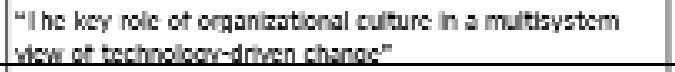 & $\begin{array}{l}\text { Intemstional journal of intermation } \\
\text { Imansoemant }\end{array}$ & Nolikulo \\
\hline $\begin{array}{l}\text { Candod, M.; Hodinguez, t. } \\
\text { M: } \\
\text { Mateos, U., }\end{array}$ & $\begin{array}{l}\text { "Infomwatian policiss in Spain Towards the new } \\
\text { information socisty" }\end{array}$ & I that & Articiala \\
\hline Qbours, $c: U ;$;ndreu, $K$. & "Sharng knowledge scross boundanes" & Joumal of intormation technology & Noticulo \\
\hline 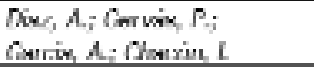 & 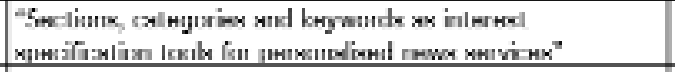 & Orilhe infonmatian revicw & Articula \\
\hline 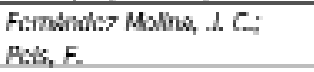 & 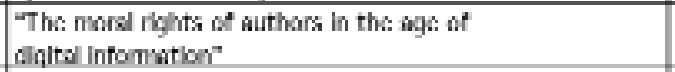 & $\begin{array}{l}\text { Wumal of the Americson Society for } \\
\text { information Sckence and Terhnalosy }\end{array}$ & Articula \\
\hline 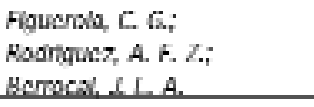 & $\begin{array}{l}\text { "Nutornatus vs manual categonsation of documents } \\
\text { it Spaniaft" }\end{array}$ & 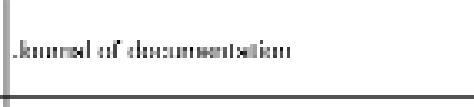 & Acliabi \\
\hline Grardiols, $L ;$ ismes, $1 . L$ & 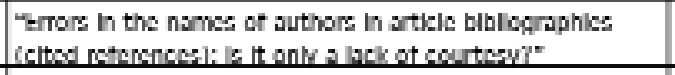 & Medicina clinca & Carta \\
\hline $\begin{array}{l}\text { Gucrero, V. P.; } \\
\text { Mans Ansoin. }\end{array}$ & 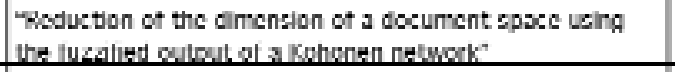 & 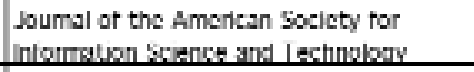 & Nolikulo \\
\hline Herrero Wiodina, E. & 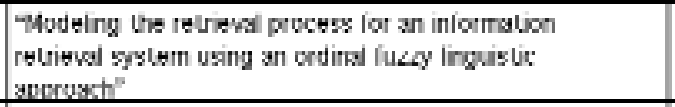 & 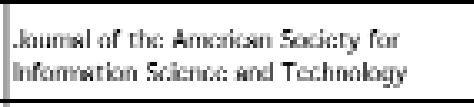 & Artoculo \\
\hline $\begin{array}{l}\text { Hernero Solans, V.; } \\
\text { Moya Anogon, f. }\end{array}$ & 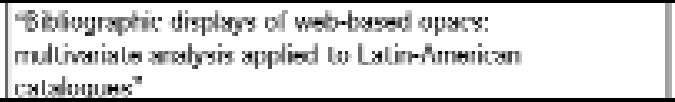 & Libri & Nelikulo \\
\hline 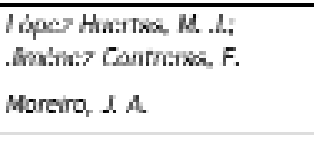 & 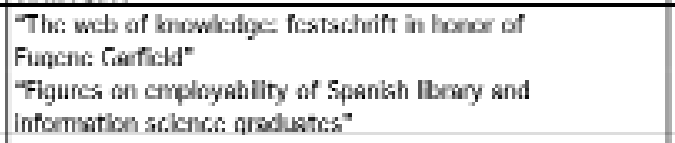 & $\begin{array}{l}\text { Knawledge organibation } \\
\text { Lubri }\end{array}$ & Articulo \\
\hline $\begin{array}{l}\text { Marilh, F.; Fondons, M.; } \\
\text { Sioncz. }\end{array}$ & $\begin{array}{l}\text { "An appenach to Intcrilsciplinarty blblommetril. } \\
\text { Indkatars" }\end{array}$ & Sicientometncs & Neticulo \\
\hline 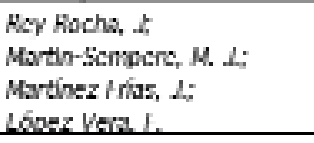 & $\begin{array}{l}\text { "Some mituses of loumal impsct foctor in rescorch } \\
\text { evalustion" }\end{array}$ & Cortex & Lditornal \\
\hline 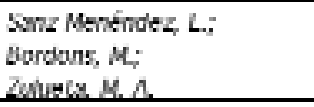 & 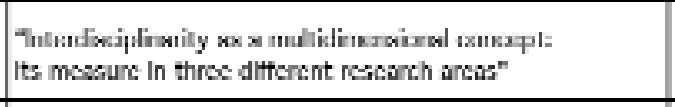 & Rescarch cveluation & Articula \\
\hline 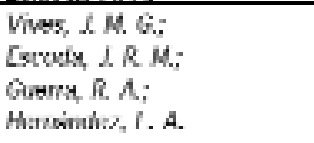 & $\begin{array}{l}\text { "A method fon the norr-destructine andysis of papent } \\
\text { based on reflectance and viscosity" }\end{array}$ & $\begin{array}{l}\text { Restourator. International foumal for } \\
\text { the preservation of Ilbrary and archival } \\
\text { material }\end{array}$ & Articulo \\
\hline
\end{tabular}

Cuadro 11. Trabajos publicados por autores españoles de ByD en revistas indizadas por el Institute for Scientific Information (2001-2002). 
te una masa crítica de información abundante y cuando deviene en incontrolable e inaccesible. El mal que las aqueja es el de la actualización. Una consulta ejecutada el 16-12-02 produce 0 documentos en $\mathrm{Docu}$ med, 32 en Isoc-ByD, 89 en Bedoc, 103 en Bibliografía de archivos.

No se puede finiquitar este apartado sin aludir a un cuerpo de literatura que, aunque cuantitativamente es pequeño, cualitativamente no lo es tanto. Me refiero a las publicaciones de los investigadores españoles del ámbito de la ByD que han sido difundidas a través de revistas internacionales, entendiéndose por tales las que son recogidas por las bases de datos del ISI (cuadro 11). Se acaba de publicar un trabajo donde se valora la producción científica en estas coordenadas desde 1992 hasta $2001^{1}$.

\section{La investigación}

Es la base sobre la que se construye una ciencia y la principal herramienta con la que cuenta una profesión para resolver sus problemas. La capacidad que las disciplinas documentales tienen de generar investigación puede medirse en los siguientes términos:

- fijando la cantidad de tesis doctorales producidas en el campo;

-analizando el porcentaje de artículos y comunicaciones de investigación publicado tanto en revistas científicas como congresos y,

- determinando la cantidad de proyectos de investigación que ha conseguido financiar en las distintas convocatorias europeas, nacionales, regionales y locales.

\section{Tesis doctorales.}

Aparte de representar la culminación del ciclo formativo de un estudiante, es el primer trabajo científico de un investigador, aquél que abre las puertas al mundo de la investigación, y seguramente uno de los que más esfuerzos y recursos (sobre todo humanos y de tiempo) consume en su vida. Pero ante todo es, o debería ser, un trabajo de investigación original.

Las dificultades comentadas con anterioridad para la identificación de tesis doctorales de CD leídas en 2002 obliga a ser cautos a la hora de proporcionar una cifra definitiva. En el cuadro 12 se listan las 25 tesis defendidas en departamentos y centros de ByD. Ciertamente el número de tesis que versen de cualquiera de las disciplinas documentales debe ser mayor. Basándome en estudios anteriores se puede estimar que el número total oscile entre 35 y 40 para 2002.

Estamos ante una cifra realmente importante, sobre todo si se compara con lo que era la situación de hace unos años y que es consecuencia entre otras razones de:

- La irrupción de las facultades y departamentos de ByD como productores de tesis, especialmente en el último lustro. La definitiva consolidación de un marco docente completo para las ciencias de la documentación: diplomatura desde 1983, licenciatura desde 1994 y doctorado (la práctica totalidad de los programas han nacido en los últimos cinco años). La existencia de más de una docena de programas de doctorado, con más de 200 alumnos inscritos, es un factor clave para la creación de una masa crítica de investigadores que dispongan de las herramientas metodológicas apropiadas para iniciar investigaciones, y asegura un ritmo importante en la producción de tesis en los años venideros.

-Un factor coyuntural, que no podemos desechar, es la aprobación de un nuevo marco jurídico para la universidad española. La $L O U$ ha fijado, entre otras cosas, una nueva estructura y composición de los órganos de gobierno y de representación, un nuevo procedimiento de selección y promoción del profesorado, un cambio en la categorización del personal docente con la creación de nuevas figuras contractuales. Con la nueva legislación, el grado de doctor se ha convertido no sólo en la llave que abre la carrera académica y asegura la promoción personal, sino que además, en muchos casos se ha erigido en requisito imprescindible para acceder a los órganos de poder universitario. Esto ha generado un desasosiego entre los becarios y el profesorado no doctor que explica, en parte, esa súbita eclosión en la lectura de tesis doctorales, en algunos casos realizada de forma apresurada.

- Conviene también destacar el papel jugado por la creciente capacidad de los departamentos en captar financiación para los programas de investigación propios (becas, proyectos, etc.).

Otros rasgos que merecen ser destacados de las tesis leídas en 2002 son los siguientes:

-A diferencia de lo que venía ocurriendo anteriormente, la mayoría se han gestado dentro de los propios departamentos y facultades de ByD.

-Esto ha propiciado un cambio en las perspectivas, las estrategias metodológicas y los contenidos de las tesis. El acento se pone más en los intereses de la profesión bibliotecaria y documental (servicios bibliotecarios y técnicas de almacenamiento y recuperación de información) que en los ámbitos temáticos de las disciplinas donde se originaban anteriormente la mayor parte de las tesis del campo (humanidades, biomedicina, periodismo). Las tesis bibliométricas, las compilaciones bibliográficas y los inventarios de coleccio- 


\begin{tabular}{|c|c|c|c|}
\hline III un & Coninu If len:lure & What urateats & IMrmatiar \\
\hline 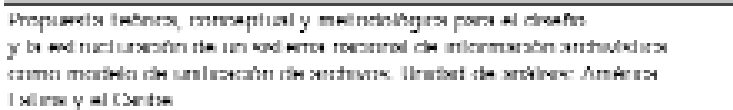 & uc3M. Doco. Byo & Lue Fornondo dotn Garclo & Me Paz Mortin Fozudio Canpilloc \\
\hline 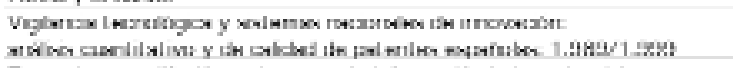 & UC3M. Doro. Byo & M" Joet Ayves stnchez & 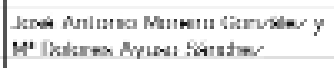 \\
\hline 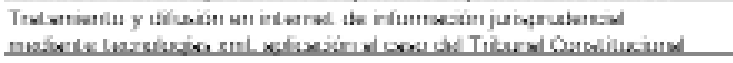 & ucsu upta Byo & Bontoco Martin Gaisn & Tombs J. Nogoles Hores \\
\hline 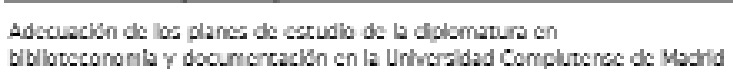 & 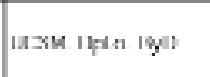 & 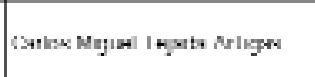 & 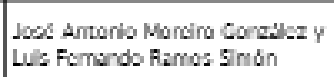 \\
\hline 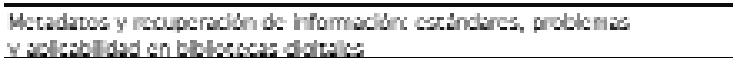 & 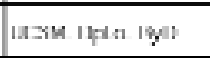 & tus Me marnion lantrigin/ & Jereat Nninna Munem Girnstes \\
\hline 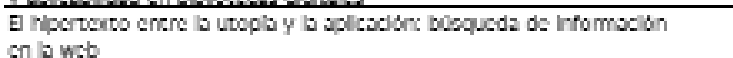 & 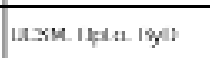 & 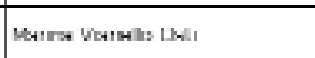 & 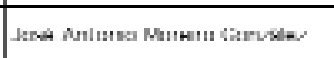 \\
\hline 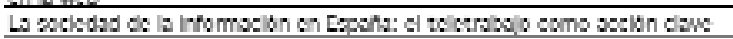 & UC3M. Doco. ByD & Ans Marto Mordice Garclo & Marocder Candod Scbestidn \\
\hline 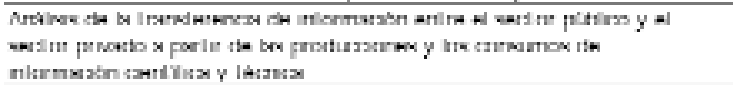 & Uс3М. Dpro Byo & Des Gintencz Tolodo & Adocivide Fombn Romen \\
\hline 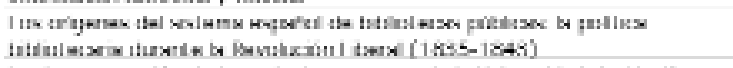 & Uс3M. Dora Byo & Genvro Lue Goreb Lopez & 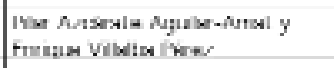 \\
\hline 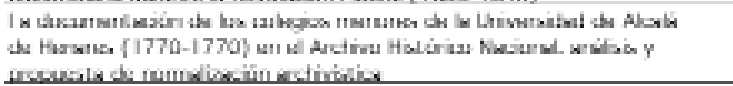 & Ir:su |lptn lyot & 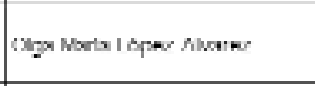 & I menia Vibelta Bkes \\
\hline 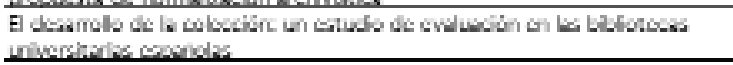 & 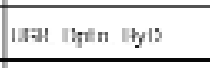 & 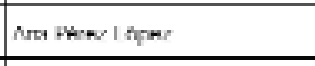 & I No rim Mrys Armginn \\
\hline 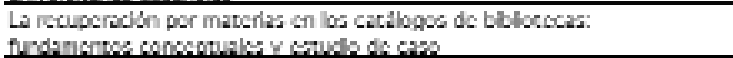 & 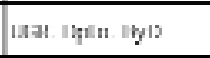 & I IEx vath lliacty & I No ram Mryax Armginn \\
\hline 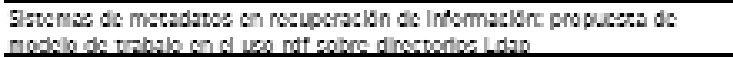 & IAat. Inquin. |ty|2 & 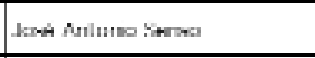 & I Wa ian Mayx Armginn \\
\hline 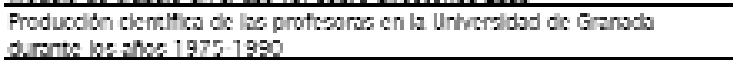 & LCA. Opku. AyD & Antw Matur & butad an Ternon \\
\hline Lo forma documental ded conthendo: un modelo pora su representsolon & UGR. Dpto. ByD & Monco laquerds & Joes M equisto y Felox Sogredo \\
\hline 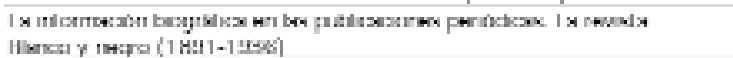 & uCM. Opto. ByD & Poquel Golg Gindncz & Joot Lue dal Flo sodoml \\
\hline 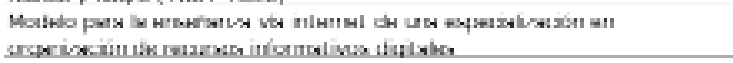 & UCM. Opto. ByD & Roberto Garouno ver & Jose Lopez Yepes \\
\hline 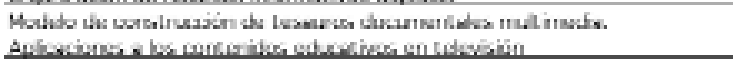 & ITM Opto Byl & Catains Names Dens & Jion Nmtons Mortirez Comeche \\
\hline 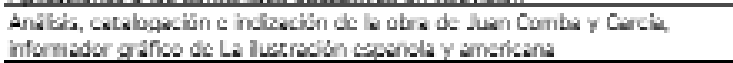 & $\begin{array}{l}\text { Scvils. Focutad de } \\
\text { Coninicseidn }\end{array}$ & Mupad L. Buisu Mairuace & Fida tad Vulat Cosaleminus \\
\hline 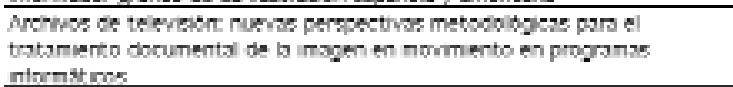 & Ueal. Doco. Byo & Joroc Caldera Serrano & Me victorla Nu'o Moral \\
\hline 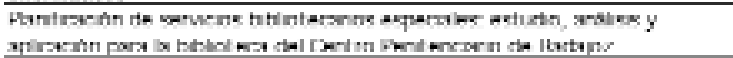 & Ueal. Doco Byo & Margarta PLrcz Puldo & Marta do la Mano Gorzalsz \\
\hline 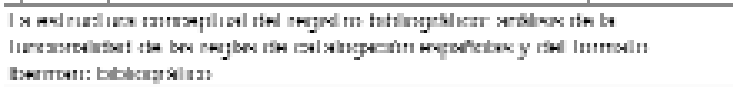 & Uesi. Dpra Byo & Ano Bekn Rlos Hilono & Joot Amtonio Frtse Montoys \\
\hline Orlpenes de botogrytlo en Murtiv: 1939-1920 & UNU. Opto. ByD & 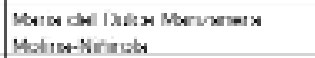 & Joet vioente Rodriguez Munoz \\
\hline 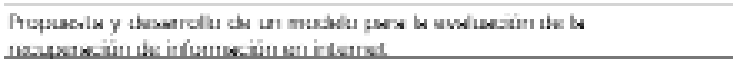 & UMU. Opto. ByD & 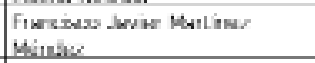 & Jose vioente Rodriguez MuAor \\
\hline 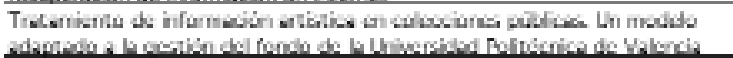 & IMII Unten |By|s & 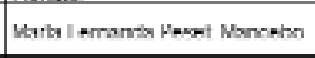 & Jenet Visente Montrigiez Minse \\
\hline 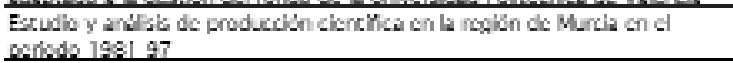 & 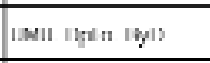 & twer Mifmo Mina & 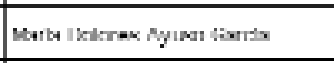 \\
\hline 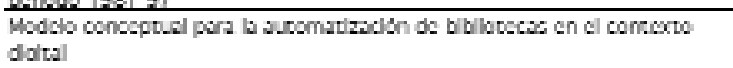 & LMU. Op:o. BYD & Tomaz Soorin PLrez & Joos Vocmte Rodripucz Munoz \\
\hline
\end{tabular}

Cuadro 12. Tesis españolas defendidas en facultades y departamentos de biblioteconomía y documentación españoles en 2002.

*UC3M : Universidad Carlos III de Madrid. UGR: Universidad de Granada. UCM: Universidad Complutense de Madrid. USA L: Universidad de Salamanca. UMU: Universidad de Murcia.

Fuente: elaboración propia.

nes archivísticas han dejado de ser las dominantes como puede apreciarse en el cuadro 12.

- También se advierten interesantes cambios en los ámbitos geográficos e institucionales en los que se gestan las tesis. Las universidades de Valencia y Complutense ya no son los principales centros de lectura de tesis. La Universidad Carlos III, con más de un tercio del total, seguida por la de Granada son los centros más activos.

-Entre los autores predominan aquellos que ya poseen una vinculación con el mundo universitario: profesores o becarios de investigación.

—En cuanto a su dirección, se aprecia un relevo generacional. López Piñero, ya jubilado, o Félix Sa- gredo y José López Yepes han cedido su papel protagonista en la dirección de tesis. Se observa asimismo, una concentración en las direcciones en torno a nuevos profesores del área (José Antonio Moreiro, Félix de Moya y José Vicente Muñoz, principalmente) muy significativa por lo que representa de reconocimiento y encomiable por la ingente capacidad de trabajo desplegada para poder dirigir tantos trabajos, tan distintos y tan distantes entre sí.

\section{Trabajos de investigación en revistas y actas de congresos.}

Ambas, y sobre todo las actas (como ocurre en disciplinas jóvenes como la nuestra) constituyen los principales vehículos para trasladar los resultados de la in- 
vestigación. Un análisis de contenido exhaustivo de todas las revistas y actas de congreso publicadas en España en 2002 desborda los estrechos límites de este trabajo. Es por lo que se ha circunscrito el estudio a las once revistas más consolidadas de la especialidad en España.

El análisis de contenido de la sección de artículos de las susodichas publicaciones periódicas (tabla 7) muestra que en 2002 el 39\% de los artículos publicados son trabajos de investigación, entendiendo por tales aquellos que tienen el propósito de aportar conocimiento novedoso, es decir, original y no conocido, utilizando el método científico para adquirirlo, es decir, ateniéndose a un procedimiento sistemático y empleando una metodología de recogida y tratamiento de los datos específica. Se trata de un porcentaje muy similar al encontrado en $1998(43 \%)^{2}$. Este dato demostraría que la capacidad productiva de investigación en la ByD española, que había despegado definitivamente a comienzos de la década de los noventa, se encuentra estabilizada en los últimos años en unos valores satisfactorios teniendo en cuenta la juventud de la disciplina. La Revista Española de Documentación Científica sigue siendo la publicación periódica con un perfil más investigador.

\section{Proyectos de investigación.}

Hasta hoy, sólo el estudio de Mercedes Caridad et al. ${ }^{3}$, ha intentado cuantificar y valorar la capacidad del área documental a la hora de desarrollar proyectos de investigación financiados por las distintas administraciones y empresas. Dicho trabajo se centró exclusivamente en Madrid y Barcelona, en parte debido a la extraordinaria dificultad de identificar con precisión los proyectos financiados bien porque la información no es accesible o se encuentra muy dispersa. Sirva de ejemplo el hecho de que la base de datos de proyectos

\begin{tabular}{|c|c|}
\hline Revistas & Articulas irıvestigación \% \\
\hline Anales de documentación & 40 \\
\hline $\begin{array}{l}\text { BiD: textos uriversitaris de biblioteconornia } i \\
\text { documentació }\end{array}$ & 71 \\
\hline Boletín de la Anabiad * & 30 \\
\hline Boletín de la Asociación Andaliza de Bibliotecarios & 27 \\
\hline Documentación de las cienciass de les informesción & 18 \\
\hline El profesional de a información (EPI) & 35 \\
\hline Itern & 44 \\
\hline Métodos de informasción & 13 \\
\hline $\begin{array}{l}\text { Papeles médicos. Revistas de las Sociededad Esparínolas } \\
\text { de Docasmentación Médicas }\end{array}$ & 56 \\
\hline Revista española de documentación científica & 100 \\
\hline Revista general de información y documentación & 36 \\
\hline
\end{tabular}

Tabla 7. Porcentaje de trabajos de investigación publicados en 2002 en once revistas españolas de biblioteconomía y documentación.

* Datos referidos al volumen de 2001.

Fuente: elaboración propia. del Plan nacional $I+D+I$ que, anteriormente era mantenida por la extinta Secretaría de Estado de Universidades e Investigación, dejó de ser consultable en línea para el público general. No estaría demás, mientras se subsanan estas deficiencias, que los departamentos universitarios, las unidades de información y sociedades científicas promotoras de proyectos colocaran información al respecto en sus sitios web, tal como hace la Universidad Carlos III, la Facultat de Biblioteconomia i Documentació de Barcelona o el Cindoc. De momento, creo que a día de hoy y hasta que no se realice un análisis pormenorizado de esta cuestión, se pueden suscribir literalmente las conclusiones alcanzadas por el citado estudio:

- La financiación de los proyectos de investigación del área ha procedido, en su mayoría, de fondos públicos. Tales fondos provienen, en buena medida, del Estado, a través de la [ya fenecida] Cicyt y, en otros casos, de la propia universidad que acoge a los investigadores, siendo reducida la financiación autonómica. [Si bien es verdad que ésta ha crecido últimamente una vez que las comunidades autónomas han asumido transferencias al respecto. Véase el caso de los planes regionales de investigación de Andalucía, Extremadura, Comunidad Valenciana, Cataluña, etc.]. Mucho más reducida es la financiación proveniente de la Unión Europea y de la empresa privada.

-Buena parte de los proyectos (...) son abordados por investigadores del mismo departamento, siendo menor el número de colaboraciones entre departamentos de nuestro área con otros de la misma institución y, más reducido, el índice de participaciones en proyectos con instituciones académicas fuera de España.

- Las administraciones públicas que dirigen la investigación en España engloban la actividad de nuestro área docente e investigadora dentro de las disciplinas de ciencias sociales y humanidades, pese a lo cual el índice de proyectos relacionados directa o indirectamente con las tecnologías de la información es más que notable.

- La cuantía de los proyectos es bastante baja".

A todo ello cabría añadir, y es justo reconocerlo, el especial protagonismo desempeñado por el Cindoc que, en su conjunto, es la institución que más proyectos de investigación ha desarrollado y más financiación ha captado tanto a nivel nacional como internacional. 


\section{Conclusiones}

La radiografía obtenida del análisis del sector documental español en 2002 es el siguiente:

1. La infraestructura documental española, aunque todavía no plenamente homologable a los países de nuestro entorno, edificada en los últimos 30 años, ha crecido vertiginosamente. Está conformada principalmente por centros de tamaño pequeño o mediano siendo financiada fundamentalmente por la administración pública. Cataluña, Madrid, Andalucía y la Comunidad Valenciana cuentan con la infraestructura bibliotecaria más abundante y consolidada. Desde el punto de vista de la archivística, por razones históricas, se presenta una distribución geográfica e institucional distinta.

2. La administración documental responde a la estructura del estado español en comunidades autónomas. Es joven y, con su adscripción al ámbito institucional de la educación y la cultura, ha reproducido con ligeros matices el modelo organizativo imperante en la administración central.

3. El colectivo profesional es ya numeroso. Ha crecido de manera importante en las últimas décadas. Las estadísticas oficiales nos hablan de un personal en el que predomina la dedicación plena, excepto en las bibliotecas públicas, sin formación universitaria especializada en ByD.

4. En su conjunto, el grado de organización social de la profesión es elevado. Existe un número de corporaciones profesionales nada desdeñable y de carácter especializado. Es el sector bibliotecario el más organizado. Los rasgos más novedosos en el ámbito del asociacionismo son:

- La proliferación de organizaciones ligadas al sector de la biblioteca escolar (cinco); todas aparecidas en el último lustro, y que son un síntoma de que está surgiendo una nueva comunidad que aspira a lograr identidad propia y que necesita defender sus intereses en un sector descuidado históricamente en España.

- La creciente importancia de las asociaciones de archiveros que aspiran a desgajarse definitivamente del resto de las ramas. Es el embrión de una nueva comunidad profesional o científica con personalidad propia.

- Las comunidades autónomas que cuentan con una infraestructura documental más numerosa (Cataluña, Andalucía, Comunidad Valenciana) son las que a su vez cuentan con más organizaciones y que cubren de forma diferenciada los tres sectores documentales (archivos, bibliotecas y documentación). Aunque a decir verdad, sólo en Cataluña puede afirmarse que la profesión esté realmente vertebrada y con una organización social sólida, como puede verse por las altas tasas de afiliación que mantiene.
- Los espacios con que cuenta la profesión para reunirse (congresos, jornadas, etc.) son cada vez más numerosos, preferentemente organizados por las asociaciones profesionales y con una orientación temática especializada.

\section{En el campo educativo cabe destacar:}

- La existencia de una formación completa en los tres ciclos, en casi todas las zonas del país. El mapa de centros es coherente excepto el caso del País Vasco, comunidad de indudable peso económico y social, que no tiene su reflejo en el sector educativo.

- Se observa en general un estancamiento en las matriculaciones y graduaciones, que es muy acusado en la diplomatura. La licenciatura se salva de este declive ya que ofrece un perfil más atractivo. Este estancamiento podría conducir al cierre de algún centro en un futuro próximo.

- Cabe destacar la importancia que va a tener, si no lo está teniendo ya, la enseñanza virtual, que es el escenario donde se producirá una competencia más fuerte entre las universidades. La irrupción de la $U O C$ es un "aviso para navegantes".

- El retrato robot del profesorado es el siguiente: joven, no permanente, no doctor, con formación específica.

6. Hoy día contamos con numerosos canales de comunicación científica: editoriales especializadas, boletines informativos, revistas científicas, congresos y listas de discusión. La mayoría son auspiciados por asociaciones profesionales y están especializados, lo cual es un signo de madurez.

7. Como consecuencia de lo anterior la literatura científica y profesional es abundante (unas $1.000 \mathrm{pu}$ blicaciones al año). De ello da testimonio la existencia de seis bases de datos bibliográficas especializadas en su control.

8. En cuanto a la investigación, empezamos a contar con una masa crítica de investigadores con formación específica en el área y con herramientas metodológicas suficientes para producir investigación de interés. Cada día se leen más tesis doctorales realizadas desde y para el área documental así como se publica más investigación y se financian más proyectos.

En líneas generales podemos decir que el colectivo bibliotecario es el más vertebrado: cuenta con una infraestructura mayor, más efectivos, más medios de comunicación, más literatura circulante y más investigación producida. Es lógico ya que estamos ante la comunidad profesional de mayor tamaño. A lo largo de este trabajo se han aportado datos que hablan de la 
institucionalización social del resto de los sectores documentales, especialmente de la rama archivística.

La crisis en Fesabid, la refundación de Anabad, el proceso de convergencia en Andalucía $(A A B / A A D)$, la refundación en Cataluña del Cobdc (en el que se fusionó en 1999 la Sociedad Catalana de Documentación e Información, Socadi), la creación de un colegio profesional en Andalucía, la pretensión de crear uno nuevo en Valencia, la solicitud de crear un nueva titulación de archivística... son claros signos de cambios que, a mi entender, se avecinan y de movimientos telúricos que afectan a las propias bases de la profesión y la disciplina en España.

Durante mucho tiempo defendí la necesidad de "crear una tribu para no ser clanes". En momentos de alumbramiento (nuestro caso) se necesita, ante todo unión, arropamiento, sumar más que restar, no podíamos ser pocos y divididos. El asentamiento de una tribu documental defendería mejor su espacio social que los clanes. Sólo cuando el campo madurara, por crecimiento cuantitativo de sus propios efectivos, se estaría en condiciones de dividirlo. Ésta ha sido la situación en España hasta la última década del siglo pasado. La profesión agrupada en asociaciones compactas pero con especialidades, la enseñanza armonizada y los cauces de comunicación unificados. No atentaba al sentido común, hasta ese momento, que las profesiones que se han encargado desde los albores de la historia de la conservación, almacenamiento, tratamiento y difusión de la información-documentación hayan estado agrupadas. Su materia prima es básicamente la misma: el documento (entendido como soporte+información), y los procesos de tratamiento y las tecnologías que les dotaban de corporeidad, también. Ocultar o minimizar las diferencias, en esos momentos históricos, no significaba borrarlas; todos sabemos que los documentos y los circuitos de comunicación archivísticos (producción, distribución y consumo) son de naturaleza claramente distinta a los bibliotecario-documentales. Los documentos de archivo, que son únicos, singulares, surgidos al calor de las actividades personales o institucionales, distribuidos por canales inter- nos, recibidos y consumidos por usuarios y clientes muy singulares, requieren unas herramientas de tratamiento que conducen a productos documentales distintos, aunque compartiendo unas bases tecnológicas similares.

Pero dichas diferencias conceptuales necesitan, para ser trasladadas a divergencias sociales, procesos de maduración. Creo que ha llegado el momento. Hay signos inequívocos, por las informaciones aquí expuestas, de que asistimos a un proceso de gemelización, sobre todo, del campo archivístico: asentamiento de una infraestructura documental y con unos órganos político-administrativos diferenciados; constitución de un cuerpo profesional autónomo, suficientemente numeroso para crear sus propios espacios en asociaciones profesionales distintas, con cauces de comunicación grupal propios (congresos) y de expresión pública (boletines, revistas y foros electrónicos) particulares. Sólo falta el reconocimiento académico: la creación de una licenciatura. Es un elemento clave en el proceso de institucionalización social de un nueva disciplina. Es el momento de apoyar dicha iniciativa. Toda la tribu se verá beneficiada. Otras especialidades como la documentación médica, empiezan también a construir su propio espacio, pero todavía no ha madurado su vertebración.

\section{Notas}

1. Jiménez Contreras, E. "La aportación española a la producción científica internacional en biblioteconomía y documentación: balance de diez años (1992-2001)". En: BiD: textos universitaris de biblioteconomia i documentació, 2002, n. 9. Consultado en 07-02-02.

http://www.ub.es/biblio/bid

2. Delgado López-Cózar, E. La investigación en biblioteconomía y documentación. Gijón: Ediciones Trea, 2002. Isbn 84-9704-041-4.

3. Caridad Sebastián, M.; Moreiro González, J. A.; Martín Galán, B. Rodríguez Mateos, D. "Los proyectos universitarios de investigación en biblioteconomía y documentación: estado de la cuestión en Madrid y Cataluña". En: Encuentro británico/español de profesores de biblioteconomía y documentación, 2000. Consultado en 07-02-2002.

http://rayuela.uc3m.es/ bmartin/publicaciones/hisp_brit2000.pdf

Emilio Delgado López-Cózar, Departamento de Biblioteconomía y Documentación, Facultad de Biblioteconomía y Documentación, Universidad de Granada.

edelgado@ugr.es

\section{Versión online de EPI}

Existe una versión electrónica de El profesional de la información, de uso gratuito para la mayoría de los suscriptores (empresas, organismos, instituciones), que pueden acceder a través de internet a los textos completos y materiales gráficos publicados en la revista.

Más información en:

http://www.szp.swets.nl/szp/journals/pi-11.htm

http://www.szp.swets.nl/szp/frameset.htm?url=/szp/eproducts/licence.htm

http://www.extenza-eps.com/extenza/contentviewing/viewJournal.do?journalld=65 